\title{
Close Proximity Soundings within Supercell Environments Obtained from the Rapid Update Cycle
}

\author{
Richard L. ThOmpson, Roger Edwards, And John A. Hart \\ Storm Prediction Center, Norman, Oklahoma \\ KimBerly L. ElMORE \\ National Severe Storms Laboratory, Norman, Oklahoma \\ PAUl MARKOWSKI \\ Department of Meteorology, The Pennsylvania State University, University Park, Pennsylvania
}

(Manuscript received 1 December 2002, in final form 31 March 2003)

\begin{abstract}
A sample of 413 soundings in close proximity to tornadic and nontornadic supercells is examined. The soundings were obtained from hourly analyses generated by the 40-km Rapid Update Cycle-2 (RUC-2) analysis and forecast system. A comparison of 149 observed soundings and collocated RUC-2 soundings in regional supercell environments reveals that the RUC-2 model analyses were reasonably accurate through much of the troposphere. The largest error tendencies were in temperatures and mixing ratios near the surface, primarily in 1-h forecast soundings immediately prior to the standard rawinsonde launches around 1200 and 0000 UTC. Overall, the RUC-2 analysis soundings appear to be a reasonable proxy for observed soundings in supercell environments.

Thermodynamic and vertical wind shear parameters derived from RUC-2 proximity soundings are evaluated for the following supercell and storm subsets: significantly tornadic supercells (54 soundings), weakly tornadic supercells (144 soundings), nontornadic supercells (215 soundings), and discrete nonsupercell storms ( 75 soundings). Findings presented herein are then compared to results from previous and ongoing proximity soundings studies. Most significantly, proximity soundings presented here reinforce the findings of previous studies in that vertical shear and moisture within $1 \mathrm{~km}$ of the ground can discriminate between nontornadic supercells and supercells producing tornadoes with F2 or greater damage. Parameters that combine measures of buoyancy, vertical shear, and low-level moisture show the strongest ability to discriminate between supercell classes.
\end{abstract}

\section{Introduction}

Proximity sounding studies have focused on the environments of severe and tornadic thunderstorms since the 1940s, beginning with the pioneering work by Showalter and Fulks (1943), Fawbush and Miller (1954), and Beebe $(1955,1958)$, where thermodynamic and kinematic environmental structures were linked to the character of subsequent severe thunderstorms. Maddox (1976) and Darkow and McCann (1977) refined some of these early investigations by constructing mean storm-relative wind profiles in the vertical from observed proximity soundings. Later work by Schaefer and Livingston (1988) created composite temperature and moisture profiles in tornado environments, as well as

Corresponding author address: Richard L. Thompson, 1313 Halley Circle, Norman, OK 73069.

E-mail: thompson@spc.noaa.gov mean hodographs, drawing from the tornado proximity sounding set collected by Darkow (1969). Finally, Davies and Johns (1993) and Johns et al. (1993) identified 242 significant tornado (F2 or greater damage) cases during the period from April 1980 through March 1991. They collected unmodified observed soundings for each case that occurred within $120 \mathrm{~km}$ and $3 \mathrm{~h}$ of an observed sounding, while cases more removed in time and space necessitated interpolation to arrive at a "representative" environment. The soundings were then used to generate measures of vertical shear and buoyancy for each tornado case.

Still, many obstacles to an advanced understanding of severe thunderstorm environments exist when considering observed proximity soundings. First, there is the nontrivial question of which time and space scales are most appropriate to represent the storm "environment" (Brooks et al. 1994a). Beebe (1958) found that soundings taken in very close time and space proximity 
to tornadoes had noticeably different vertical structure compared to proximity soundings in the antecedent preconvective environment several hours earlier. Numerical simulations by Weisman et al. (1998) demonstrated that supercells may exert influence on low-level shear and buoyancy profiles up to $30 \mathrm{~km}$ away from the storm, effectively altering what had been the prestorm environment. Apparent storm impacts on local environments have been documented during formal field experiments (e.g., Markowski et al. 1998), and have been observed by storm chasers across the Great Plains of the United States since the 1970s.

Other concerns with proximity sounding analysis include sounding sample size and storm characteristics. Maddox (1976) estimated that several hundred years may be necessary to accumulate a large sample of close proximity soundings for tornadic storms. Kerr and Darkow (1996) applied rather stringent proximity criteria (15 min before to $105 \mathrm{~min}$ after tornado time, and within $80 \mathrm{~km}$ ), though characteristics of storms were not associated with specific classes of proximity soundings due to coarse Weather Surveillance Radar-1957 (WSR57) radar reflectivity archives. A large sounding sample was collected by Rasmussen and Blanchard (1998, hereafter RB98). They considered all 0000 UTC soundings from 1992, and associated each sounding with welldocumented tornadoes, supercells that were either nontornadic or produced only brief/weak tornadoes, or lightning strikes and no severe weather. RB98 relied on 5 -cm ( 2 in.) diameter or larger hail as a proxy for supercells, and their time and space limitations were rather broad (up to $400 \mathrm{~km}$ in the inflow sector of storms, along with a time window spanning from $6 \mathrm{~h}$ prior to $3 \mathrm{~h}$ after sounding time). As a test of the RB98 supercell classification technique, we examined the National Oceanic and Atmospheric Administration (NOAA) publication Storm Data for $5 \mathrm{~cm}$ or larger hail reports from April and July of 2000. Of these hail reports, 90\% could be attributed to supercells identified in archived Weather Surveillance Radar-1988 Doppler (WSR-88D) reflectivity and storm-relative velocity imagery. However, less than two-thirds of the documented supercells during those 2 months produced hail $5 \mathrm{~cm}$ or larger, and it is also likely that most cool season supercells do not produce very large hail. Therefore, RB98 probably excluded a large number of actual supercells in their supercell sounding classification, though any biases resulting from the inclusion of supercells in their nonsevere category were likely overwhelmed by a very large sample size. Most recently, Craven et al. (2002a, hereafter $\mathrm{C} 02$ ) completed an examination of proximity soundings for the period from 1957 to 1999 . While they have created sample sizes in the thousands, their proximity criteria ( $185 \mathrm{~km}$ and $3 \mathrm{~h}$ before and after sounding time) still allow much uncertainty for individual severe events. Specific classes of severe weather cannot be attributed to specific storm types in their sample; thus, information from their proximity sounding sample does not lend itself to forecasts of specific convective storm types responsible for the severe weather. Finally, massive increases in severe weather reporting (e.g., Weiss and Vescio 1998) and temporal inconsistencies in tornado damage ratings (Brooks and Craven 2002) are problematic for proximity sounding samples covering the past several decades.

This work is an attempt to refine these past and ongoing studies by utilizing gridpoint soundings from Rapid Update Cycle-2 (RUC-2) model analyses (Benjamin et al. 2002). These RUC-2 analyses were available to forecasters at the Storm Prediction Center (SPC) on an hourly basis, which enabled collection of a reasonably large proximity sample size in a period of only a few years, as opposed to many decades for observed soundings meeting similar proximity criteria. The hourly analyses are sensitive to the accuracy of short-term model forecasts, but a primary advantage is the superior spatial and temporal resolution compared to that of the upper-air observing network across the United States. The hourly analyses can be impacted by the model convective parameterization (Grell 1993), if the scheme has been active recently at a grid point. However, the influence of the convective parameterization tends to be reduced in the absence of widespread convective precipitation, as in our cases of relatively isolated storms. Our sample of RUC-2 model close proximity soundings has the additional benefit of not being adversely impacted by changing tendencies in severe weather reporting over long time periods. Finally, we limit our examination to supercells identified using WSR-88D imagery, thus allowing direct association of sounding characteristics with specific classes of severe storms.

To accomplish our goals, we have collected a set of observed and RUC-2 analysis/forecast soundings in regional supercell environments from 1999 through 2001. Herein we document the accuracy of the RUC2 analysis soundings, and make recommendations regarding the utility of the RUC- 2 analyses in assessing environmental characteristics associated with supercells. Section 2 outlines our data collection methodology, RUC-2 sounding error characteristics are examined in section 3 , and section 4 consists of an evaluation of several common and new severe storm parameters derived from the RUC-2 proximity soundings. Results are summarized in section 5.

\section{Data and methodology}

The following right-moving supercell definitions and proximity criteria were utilized to identify supercell proximity sounding cases during real-time data collection from April 1999 through June 2001 across the conterminous United States:

1) Each storm must have displayed one or more characteristic radar reflectivity structures such as hook 
echoes, inflow notches, etc. (Browning 1964; Lemon 1977); a WSR-88D peak cyclonic (counterclockwise) azimuthal shear of $20 \mathrm{~m} \mathrm{~s}^{-1}$ or greater at the 0.5 or $1.5^{\circ}$ elevation angles across not more than 10 $\mathrm{km}$ [i.e., a minimum azimuthal shear of $0.002 \mathrm{~s}^{-1}$ in relatively coarse $1-\mathrm{km}$ resolution velocity data, similar to the Mesocyclone Detection Algorithm described in Stumpf et al. (1998)]; and persistence of cyclonic shear for at least $30 \mathrm{~min}$. All three criteria must have been met, though only the two lowest radar elevation angles were considered due to operational data constraints at the SPC.

2) Supercells were categorized as either significantly tornadic (F2 or greater tornado damage), weakly tornadic (F0-F1 tornado damage), or nontornadic. Not every supercell was included, so that our dataset would not be overly influenced by single days with large numbers of supercells. Instead, we collected an average of roughly two cases for each day where supercells were identified (413 supercells from 226 different days). All supercells of the same type were separated by at least $3 \mathrm{~h}$ and $185 \mathrm{~km}$ when multiple storms were collected during a single day.

3) Finally, a RUC-2 analysis gridpoint sounding was generated for each supercell at the analysis time closest to the most intense tornadoes with the tornadic supercells, or the time of the most intense severe weather reports with the nontornadic supercells, or at the time of the most pronounced radar signatures if no severe weather was reported. The RUC-2 analysis soundings were interpolated (bilinear between nearest four grid points) for each supercell to the closest surface observing site that was generally located upwind from the supercell at the surface, per regional observations. Surface observing sites were an option for generating soundings via the NSHARP software (Hart and Korotky 1991), which allowed relatively simple identification of each case. In an effort to eliminate so-called elevated supercells (those clearly rooted well above the surface), surface-based CAPE must have been present in each RUC-2 proximity sounding. The RUC-2 analysis grids were available at $40-\mathrm{km}$ horizontal grid spacing, on isobaric surfaces with $25-\mathrm{hPa}$ vertical resolution (e.g., 1000, 975, 950, $925 \mathrm{hPa}$, etc.) Use of the isobaric data resulted in a loss of vertical resolution near the ground (i.e., roughly nine levels in the lowest kilometer of the native hybrid sigma-isentropic coordinate system, versus four levels in the isobaric grids through the same depth). Also, contamination of the RUC-2 analysis soundings by observed and parameterized convection was limited by the relatively sparse coverage of convective precipitation in our cases. The net result was proximity soundings that were generally within $30 \mathrm{~min}$ and 40 $\mathrm{km}$ of each supercell.

Following these guidelines, a nationwide sample of
413 right-moving supercells and associated RUC-2 model analysis soundings was gathered for the period from April 1999 through June 2001 (Fig. 1a). Included in this sample were 54 significantly tornadic supercells, 144 weakly tornadic supercells, and 215 nontornadic supercells. When any of these supercells occurred within $3 \mathrm{~h}$ of a standard sounding time $(0000$ or 1200 UTC, or special soundings at 0600 and 1800 UTC), the nearest observed sounding was also archived if it had 1) surfacebased parcel CAPE (Doswell and Rasmussen 1994), 2) complete data below the equilibrium level, and 3) no obvious thermodynamic or kinematic alteration by nearby thunderstorms. Finally, for each observed sounding meeting these criteria, a RUC-2 analysis sounding valid at the time and location of the observed sounding was generated to determine how accurately the RUC-2 depicted the regional supercell environment (Fig. 1c).

The geographic distribution of the supercell proximity soundings in Fig. 1a indicates that the vast majority of the observed supercells occurred east of the Rocky Mountains, especially across the the Great Plains and Midwest. It is important to note that not all supercells were collected for each day, and the authors were unable to save storm information on a few occasions. For example, only two proximity soundings were gathered during the 3 May 1999 tornado outbreak in the plains that consisted of at least 10 supercells, while only one sounding was collected on most supercell days in a particular region. If multiple supercell types occurred in the same region (e.g., significantly tornadic and nontornadic), a RUC-2 sounding was generated for the most intense storm of each type per the criteria discussed in 3 ). Therefore, Fig. 1a is representative of the number of supercell days in a particular region. Also of note in Fig. 1a is a lack of events along the immediate coasts of the Gulf of Mexico and Atlantic Ocean. This was because all RUC-2 proximity soundings with surface pressures of $1000 \mathrm{hPa}$ or greater were truncated erroneously to $975 \mathrm{hPa}$ by a limitation in the NSHARP sounding analysis software. ${ }^{1}$ Approximately 100 lowelevation supercells, as well as more than 100 nonsupercell storms, were excluded from this study since the lowest $25-40 \mathrm{hPa}$ of each RUC-2 sounding were missing. The hourly sounding distribution (not shown) reveals an expected diurnal peak near 0000 UTC, with the vast majority of the proximity soundings confined to the period from 1800 to 0600 UTC. More variability is noted in the monthly distribution of cases (Fig. 1b), where significantly tornadic storms were more frequent during the spring, while the nontornadic and nonsupercell storms were more common in the late spring and summer months. The relative minima in June for nontornadic and nonsupercell storms can be attributed to time away from the SPC by the lead authors, where time constraints necessitated collection of the less frequent

\footnotetext{
${ }^{1}$ The truncation error affected only the model grid soundings, not the observed soundings.
} 


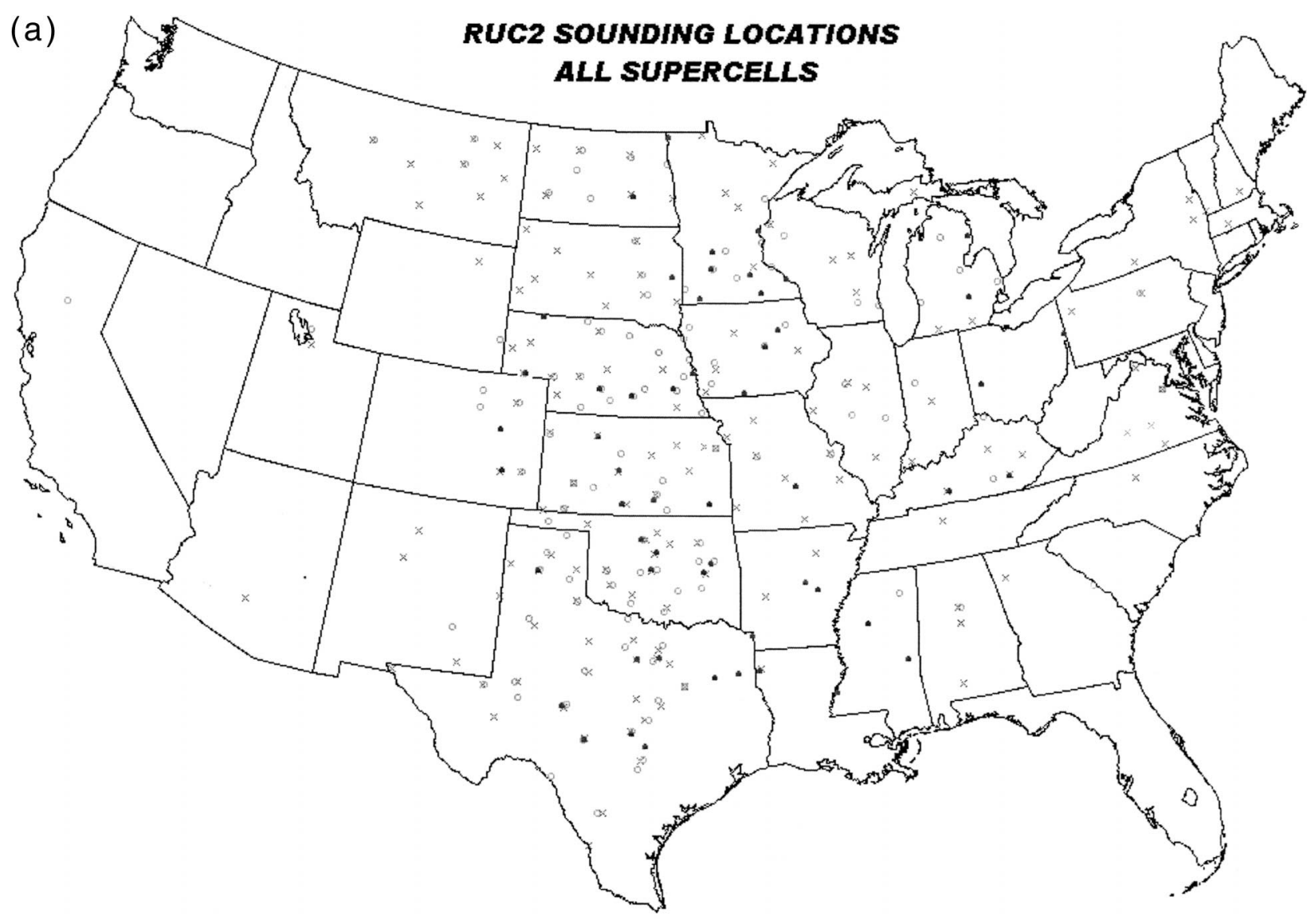

(b)

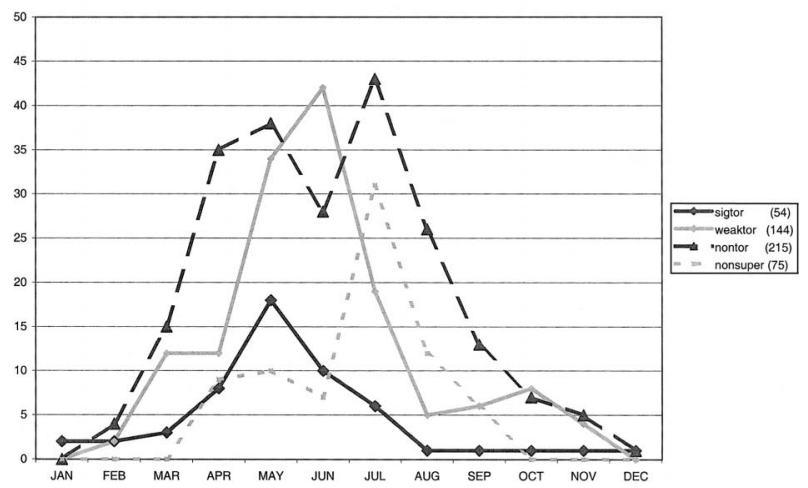

tornadic storms at the expense of nontornadic and nonsupercell events.

A primary advantage of the RUC-2 analysis soundings is their hourly availability. The RUC-2 analyses contain asynoptic data from wind profilers, aircraft temperatures, and winds (automated weather reports from commercial aircraft, ACARS); WSR-88D velocity azimuth display winds; satellite winds; surface observing networks; etc. However, the quality of these soundings can be questioned given the nonuniform observations of temperature, moisture, and winds above the surface and between the standard twice-daily soundings at 0000
FIG. 1. (a) Geographic plot of 413 RUC-2 supercell proximity sounding locations. Solid circles represent significantly tornadic supercells (F2-F5 tornado damage, 54 cases), open circles denote weakly tornadic supercells (F0-F1 tornado damage, 144 cases), and Xs mark nontornadic supercells (215 cases), (b) number of cases by month for each group, and (c) number of 0-h RUC-2 analysis soundings and observed sounding comparisons at each site (1-h forecast sounding numbers in parentheses).

and 1200 UTC. To examine the accuracy of these asynoptic RUC-2 soundings, we chose 1 -h forecasts from 2300 UTC, valid at 0000 UTC, to compare to the 0000 UTC observed soundings. Our assumption was that the 1 -h forecast, based on a RUC-2 analysis $11 \mathrm{~h}$ after the time of the previous synoptic soundings, should have been the least accurate of the day. The geographic distribution of the comparison cases is shown in Fig. 1c, which closely resembles the storm cases in Fig. 1a.

Sounding errors were computed by taking either the difference between the analysis and observed value, or between the forecast and observed value. Hence, pos- 


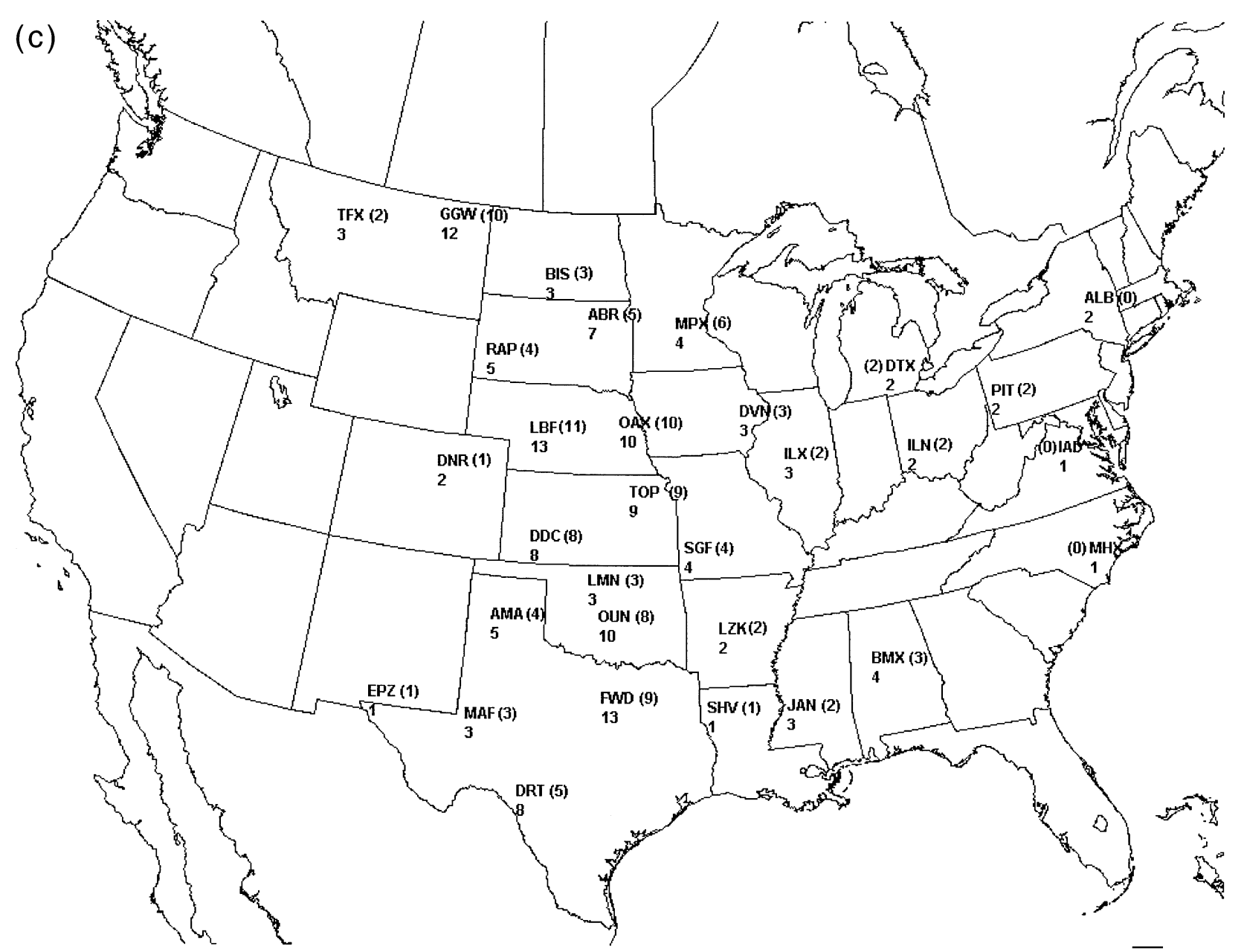

FIG. 1. (Continued)

itive (negative) errors mean that the analysis or forecast value was greater (less) than the observed value. To facilitate a consistent comparison of sounding characteristics, the observed comparison soundings were interpolated to the same $25-\mathrm{hPa}$ pressure surfaces available in the RUC-2 analyses. Confidence intervals about the mean error were computed based on the $t$ statistic (Wilks 1995). The error distributions do not deviate grossly from a normal distribution, though the error distribution tails tend to be slightly larger than what is expected from normally distributed errors. Therefore, our $95 \%$ confidence intervals may be somewhat narrow.

Errors in bulk properties (such as CAPE and vector shear magnitude) were computed in the same manner as the basic sounding variables (such as temperature). However, these errors are clearly not normally distributed. The error distribution tends to be a function of the parameter in question, and it may be partly due to the nature of some parameters. For example, CAPE cannot be negative. Hence, the median was used to estimate the overall error because it is resistant to outliers.

\section{RUC-2 sounding error characteristics}

a. Temperature, mixing ratio, and wind speed errors

Comparison soundings were collected for 149 RUC2 analysis $(0 \mathrm{~h})$ soundings (Fig. 1c), and a subset ${ }^{2}(125)$ of these analysis soundings also included the 1-h forecast soundings valid at the same time and location. The 1 -h forecast soundings were not collected routinely during the spring of 1999, thus the smaller sample size. As part of the comparison, all observed soundings were interpolated to the same $25-\mathrm{hPa}$ isobaric surfaces available in the RUC-2 analysis grids. The profile of temperature errors for the 0 -h RUC- 2 analysis soundings (Fig. 2a) reveals that the zero error was generally within the $95 \%$ confidence interval from about 850 to $400 \mathrm{hPa}$. Temperature errors were larger near the ground, with a strong tendency for model surface temperatures to be about $0.5^{\circ} \mathrm{C}$ too cool. Vertical temperature errors for the

\footnotetext{
${ }^{2}$ Initial data collection during 1999 included primarily the 0-h analysis soundings, while 1-h forecast soundings were not archived by the authors until early 2000 .
} 
(a)

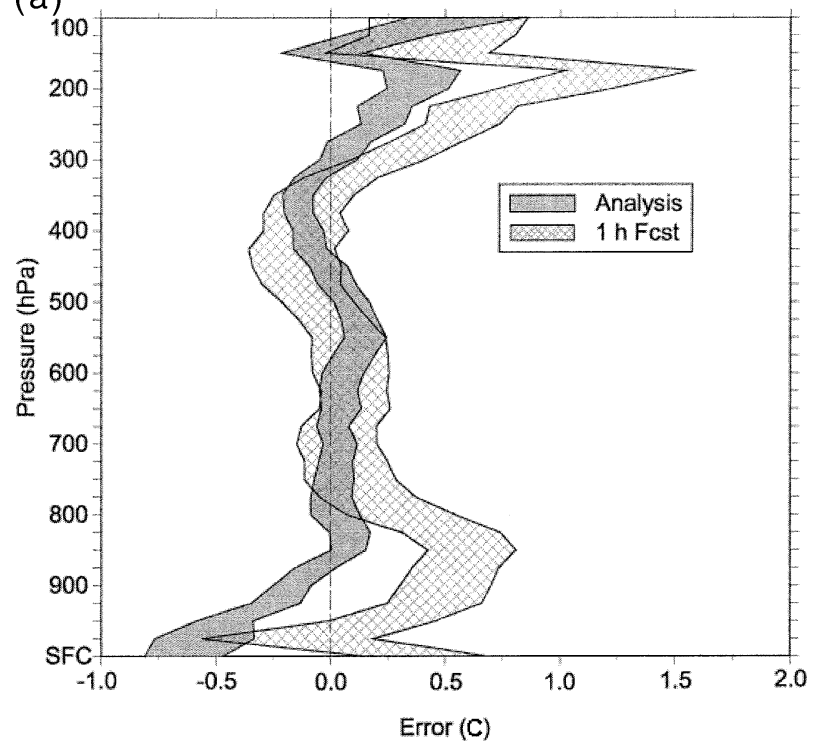

(c)

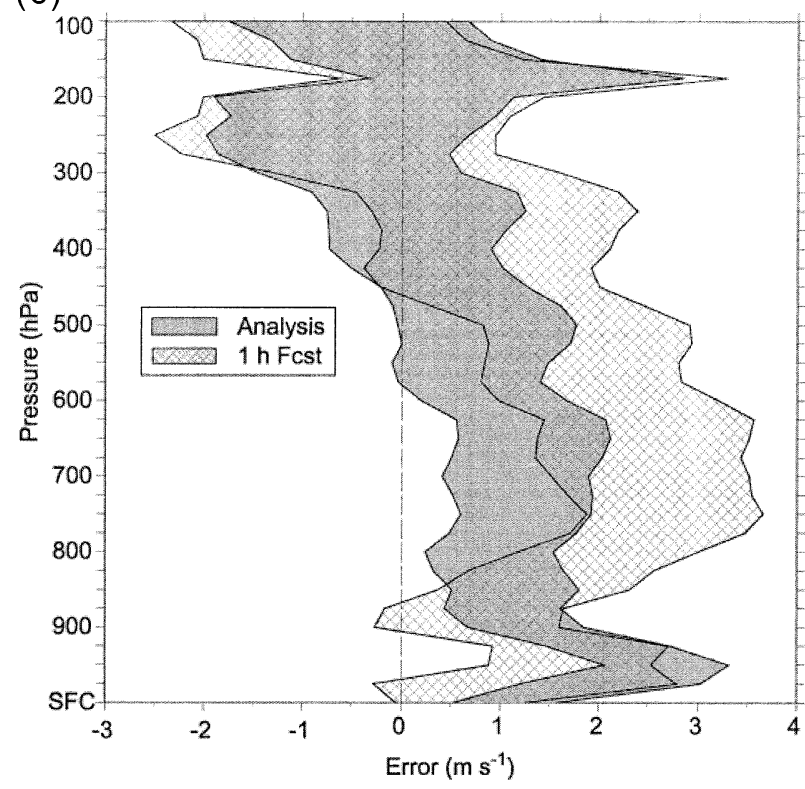

1-h RUC-2 forecast soundings (Fig. 2a) were substantially different than for the 0 -h soundings, with pronounced overforecasts (roughly $0.5^{\circ} \mathrm{C}$ ) from the surface to $800 \mathrm{hPa}$. Schwartz and Benjamin (2002b) presented evidence of a roughly $1^{\circ} \mathrm{C}$ cold bias in RUC 3 -h forecasts of surface $(2 \mathrm{~m})$ temperatures at many airport hub locations across the central and eastern United States during January 2002. Model terrain elevation and land use specifications introduced the largest errors at airport locations in mountainous areas and near coastlines in their sample, though our supercell cases occurred primarily across the Great Plains and Midwest where such errors tended to be smaller. The warm bias in our 1-h soundings may reflect a forecast bias of the RUC-2 model itself during the warm season, which is manifest (b)

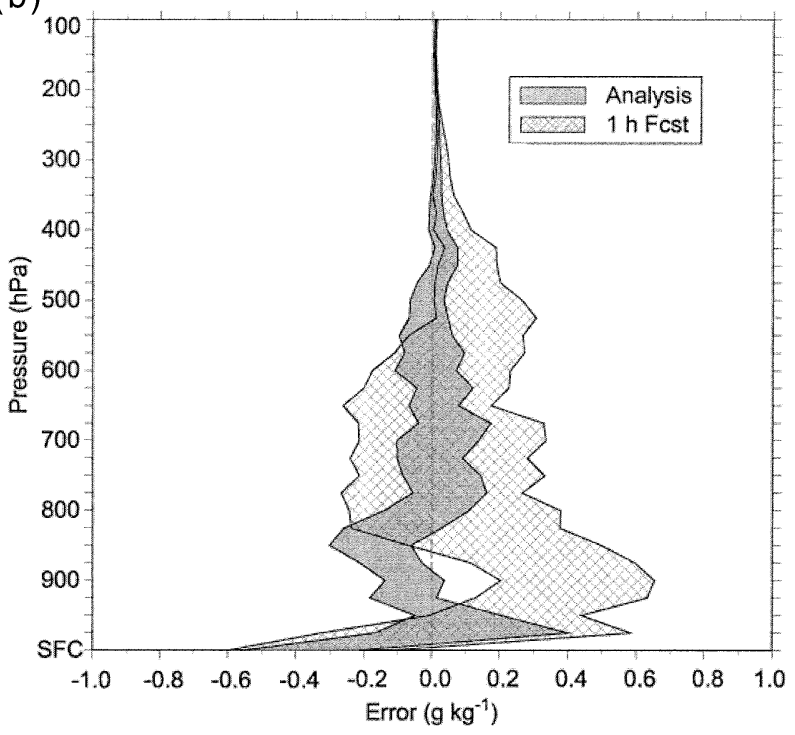

FIG. 2. Vertical profiles of the $95 \%$ confidence intervals for (a) temperature errors $\left({ }^{\circ} \mathrm{C}\right)$, (b) mixing ratio errors $\left(\mathrm{g} \mathrm{kg}^{-1}\right)$, and (c) wind speed errors $\left(\mathrm{m} \mathrm{s}^{-1}\right)$ for 149 0-h RUC-2 analysis soundings (shaded), and a subset of 1251 -h forecast soundings valid at the analysis time (hatched).

through a series of short-term RUC-2 forecasts that are well removed in time from the previous synoptic soundings (e.g., the RUC-2 analyses from about 1800 to 2300 UTC). Still, the temperatures errors were not particularly large and were of similar magnitude to the measurement accuracy of the radiosonde observations $\left(0.5^{\circ} \mathrm{C}\right.$; NOAA 2003$)$.

Mixing ratio errors (Fig. 2b) were largest near the ground with a tendency for the RUC-2 analyses to overestimate the mixing ratios by $0.1-0.2 \mathrm{~g} \mathrm{~kg}^{-1}$ immediately above the surface. The small errors above $400 \mathrm{hPa}$ are somewhat misleading since mixing ratios aloft tend to be limited by cold temperatures; thus, absolute error magnitudes are necessarily small. Dewpoint temperature errors (not shown) were largest from 400 to $100 \mathrm{hPa}$. 


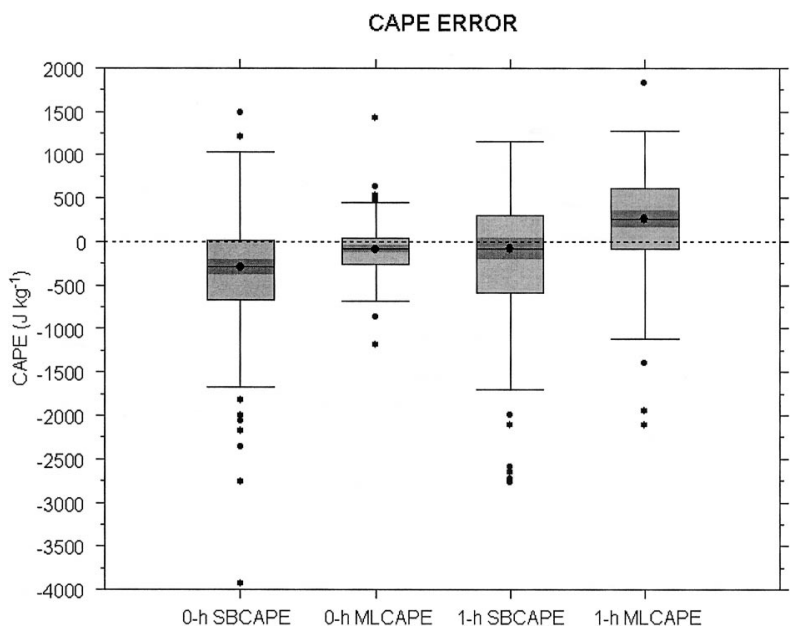

FIG. 3. Box and whiskers plot of SBCAPE and MLCAPE errors $\left(\mathrm{J} \mathrm{kg}^{-1}\right)$ for both the 0-h analysis and 1-h forecast soundings. The shaded box encloses the 25th-75th error percentiles (interquartile range), and the dark band within the interquartile range marks the 95\% confidence intervals for the median error values. The whiskers extend to the closest error value that is not more than 1.5 times the interquartile range (length of the box), and the extreme errors are marked by the solid dots above and below the whiskers.

The 1-h forecast mixing ratios were generally $0.2-0.3$ $\mathrm{g} \mathrm{kg}^{-1}$ too large near $900 \mathrm{hPa}$ (Fig. 2b), though surface values were too low by roughly the same amount. Recent work by Turner et al. (2003) documented a 5\% dry bias in the radiosondes used in National Weather Service (NWS) field offices, which is of similar magnitude to the mean RUC-2 analysis errors in this sample, as well as the relative humidity accuracy of the observed soundings (5\%; NOAA 2003).

The RUC-2 analysis wind speed tended to be about $1-2 \mathrm{~m} \mathrm{~s}^{-1}$ too strong from the surface to $400 \mathrm{hPa}$ (Fig. 2c). Despite the speed overestimates in the RUC-2, the profiles of $u$ and $v$ wind component errors (not shown) for the 0-h analysis soundings were consistent with the 1-h forecasts, with the zero error generally within the $95 \%$ confidence interval. However, there was some skew in the profiles such that the zonal (westerly) and meridional (southerly) wind components were overforecast by $0.5-1 \mathrm{~m} \mathrm{~s}^{-1}$ in the layer from the surface to about $600 \mathrm{hPa}$. Our surface wind speed errors are similar to the findings of Schwartz and Benjamin (2002b), and are of similar magnitude to the measurement accuracy of the radiosondes $\left(1.5 \mathrm{~m} \mathrm{~s}^{-1}\right.$; NOAA 2003).
In summary, the 0-h RUC-2 analyses tended to be a little too cool and dry at the surface, while the 1-h forecast soundings were too warm and moist around 900 $\mathrm{hPa}$. Both the 0 - $\mathrm{h}$ analyses and 1 -h forecast soundings tended to overestimate tropospheric wind speeds by $1-$ $2 \mathrm{~m} \mathrm{~s}^{-1}$. Contrary to our working hypothesis, the $1-\mathrm{h}$ forecast error magnitudes were not substantially larger than errors calculated from the 0 -h analysis soundings, and the asynoptic soundings appear to be sufficiently accurate to allow their inclusion in our proximity sounding sample. It is important to note that the presented error characteristics may represent a best-case scenario, and larger errors are possible away from the radiosonde sites. Of greater concern are the impacts of these basic variable errors on derived convective parameters.

\section{b. Bulk parameter errors}

Several bulk supercell sounding parameters related to CAPE and vertical shear were also examined for both the analysis and 1-h forecast soundings. In general, the surface-based CAPE (SBCAPE) values were underestimated by $300-500 \mathrm{~J} \mathrm{~kg}^{-1}$ in the 0 -h soundings (see Fig. 3 and Table 1), due to the negative biases in surface temperatures and mixing ratios (see Fig. 2a). The 1-h forecast sounding errors for SBCAPE covered a range of values similar to the 0 -h sounding errors, though the errors were more closely centered near zero as a result of minor warm and dry biases counteracting one another in the CAPE calculation. The $0-\mathrm{h} 100-\mathrm{mb}$ mean parcel CAPE (MLCAPE) errors were less biased than the SBCAPE errors, with a tight clustering of values in small range (0 to $\left.-250 \mathrm{~J} \mathrm{~kg}^{-1}\right)$.

A closer examination of the extreme outlier SBCAPE error $\left(-3930 \mathrm{~J} \mathrm{~kg}^{-1}\right)$ revealed that a near-surface "spike" in the dewpoint temperature was responsible for the difference between the observed and RUC-2 analysis soundings (Fig. 4). The MLCAPE error $\left(\sim-240 \mathrm{~J} \mathrm{~kg}^{-1}\right)$ for these same soundings shown in Fig. 4 was much smaller than the SBCAPE error. The observed moisture profile in Fig. 4 can be questioned given the surface mixed-layer depth in excess of 100 $\mathrm{hPa}$, though no additional observations were available to dispute the rapid moisture decrease just above the surface. Schwartz and Benjamin (2002a) discussed various choices in CAPE calculations and documented 3h RUC errors similar to our MLCAPE errors, and Craven et al. (2002b) found that a 100-hPa mean parcel

TABLE 1. Mean parameter values (mean), mean absolute errors (MAEs), and mean arithmetic errors (bias) for the 0- and 1-h RUC-2 comparison soundings.

\begin{tabular}{|c|c|c|c|c|c|c|}
\hline Parameter & 0-h mean & 0-h MAEs & 0 - $\mathrm{h}$ bias & 1-h mean & 1-h MAEs & 1-h bias \\
\hline SBCAPE $\left(\mathrm{J} \mathrm{kg}^{-1}\right)$ & 2529 & 570 & -373 & 2560 & 648 & -252 \\
\hline $\operatorname{MLCAPE}\left(\mathrm{J} \mathrm{kg}^{-1}\right)$ & 1655 & 218 & -99 & 1656 & 520 & 224 \\
\hline MLLCL (m AGL) & 1495 & 77 & -11 & 1508 & 190 & 3 \\
\hline $0-1-\mathrm{km}$ shear $\left(\mathrm{m} \mathrm{s}^{-1}\right)$ & 7.9 & 1.8 & -0.5 & 8.3 & 2.4 & -0.8 \\
\hline $0-6-\mathrm{km}$ shear $\left(\mathrm{m} \mathrm{s}^{-1}\right)$ & 22.9 & 2.1 & -0.3 & 23.2 & 2.6 & -0.2 \\
\hline
\end{tabular}




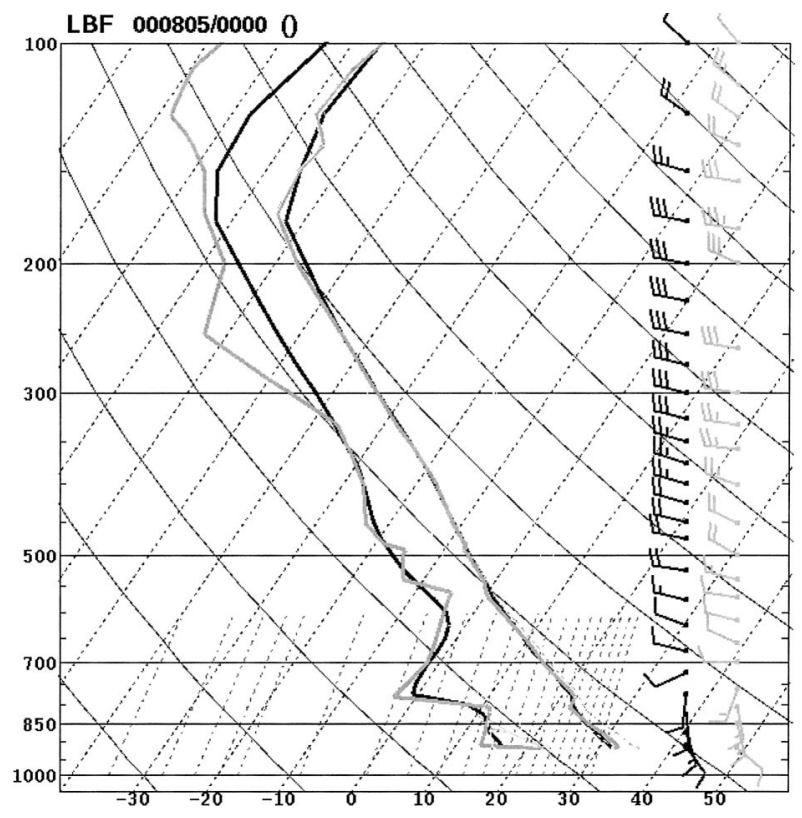

FIG. 4. Skew $T-\log p$ plot of the RUC-2 analysis sounding (black) for the extreme SBCAPE error from Fig. 3, with an overlay of the collocated observed sounding (gray).

was superior to a surface parcel in determining parcel ascent. As discussed in the previous subsection, RUC forecast errors in surface variables can be magnified by differences between observed and model terrain height, and in regions of sharp transition in land use or surface type (i.e., coastal regions). Considering the findings of the aforementioned studies, and the error characteristics of our comparison soundings, the use of a mean (100 $\mathrm{hPa}$ ) layer parcel appears to be a better choice than a surface parcel in evaluating environmental characteristics of supercell environments with RUC model proximity soundings.

The RUC-2 tended to overforecast the 1-h MLCAPE as a result of temperatures and mixing ratios being too large within the lowest $100 \mathrm{hPa}$ (cf. Figs. 2a and 2b with Fig. 3). An examination of individual comparison cases suggests that the warm and moist bias in the 1-h forecast soundings may be attributable to the RUC-2 generating a "well mixed" boundary layer that is too deep, though the specific sources of these errors in the model are unknown. Despite the apparent differences in MLCAPE error characteristics between the 0- and 1$\mathrm{h}$ forecast soundings, experience of the authors suggests that these error magnitudes are too small to have a serious impact on operational evaluation of storm environments. We believe the MLCAPE values to be less biased and more representative of the potential for deep convection than SBCAPE; hence, we have chosen MLCAPE for our proximity sounding evaluation. Similarly, mean layer lifting condesation level (MLLCL) errors (Table 1) were considered to be reasonably small and not biased in the mean, while error distributions

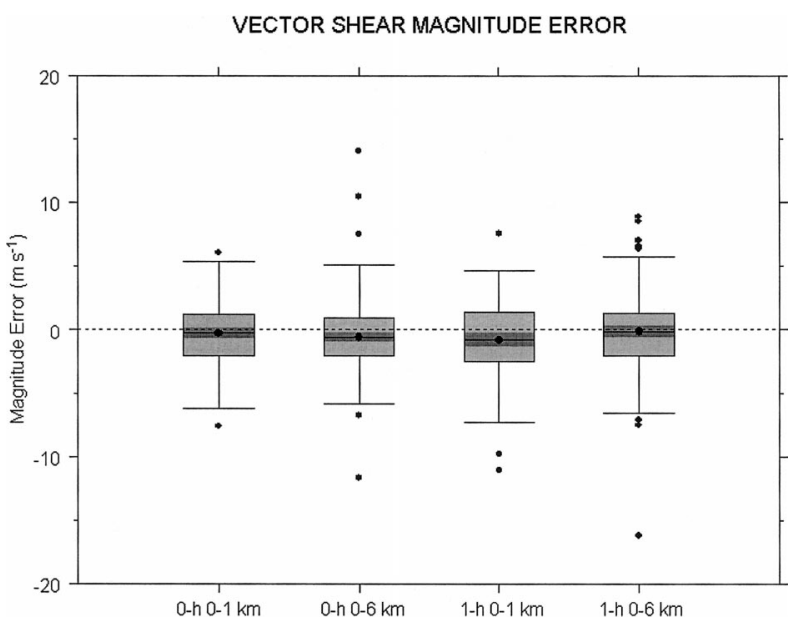

FIG. 5. Same as in Fig. 3 except for $0-1-$ and $0-6-\mathrm{km}$ vector shear magnitude error $\left(\mathrm{m} \mathrm{s}^{-1}\right)$.

(not shown) were centered near zero for both the 0 - and 1-h soundings.

Errors in vertical shear parameters, such as stormrelative helicity ${ }^{3}(\mathrm{SRH})$ and measures of deeper layer shear (e.g., 0-6-km vector shear magnitude), were more uniformly distributed than the CAPE errors. The 95\% confidence intervals for median values of $0-1$ - and 0 6-km vector shear magnitude errors (Fig. 5) are near zero error in each layer for both the 0-h analyses and 1-h forecasts, with typical error magnitudes around 2 $\mathrm{m} \mathrm{s}^{-1}$ and small mean errors (see Table 1). Similar error distributions were also documented for the $0-1$ - and 0 3-km SRH (not shown). In spite of the tendency for the RUC-2 analyses and 1-h forecasts to overestimate wind speeds throughout the troposphere in our comparison soundings, the derived shear parameters were not biased because the speed and direction errors were relatively consistent throughout the lowest $6 \mathrm{~km}$ (i.e., the surface to about $500 \mathrm{hPa}$ ). These results suggest that the our RUC-2 proximity soundings were reasonably representative of the regional supercell environments, and can be used to compare parameter distributions across the storm groupings described in section 2 .

\section{Supercell and tornado forecast parameters}

The 413 supercell proximity soundings were categorized as associated with either 1) nontornadic (215 cases), 2) weakly tornadic (F0-F1 tornado damage, 144 cases), or 3) significantly tornadic (F2-F5 tornado damage, 54 cases) supercells. In addition, a sample of 75

\footnotetext{
${ }^{3} \mathrm{SRH}$ values were calculated using storm motions estimated by the algorithm developed by Bunkers et al. (2000), since these comparison soundings were not considered to be direct proximity soundings for any particular supercell. The Bunkers algorithm is the most reliable means to estimate supercell motion that is now available in forecast operations, as independently verified by Edwards et al. (2002).
} 
MLCAPE

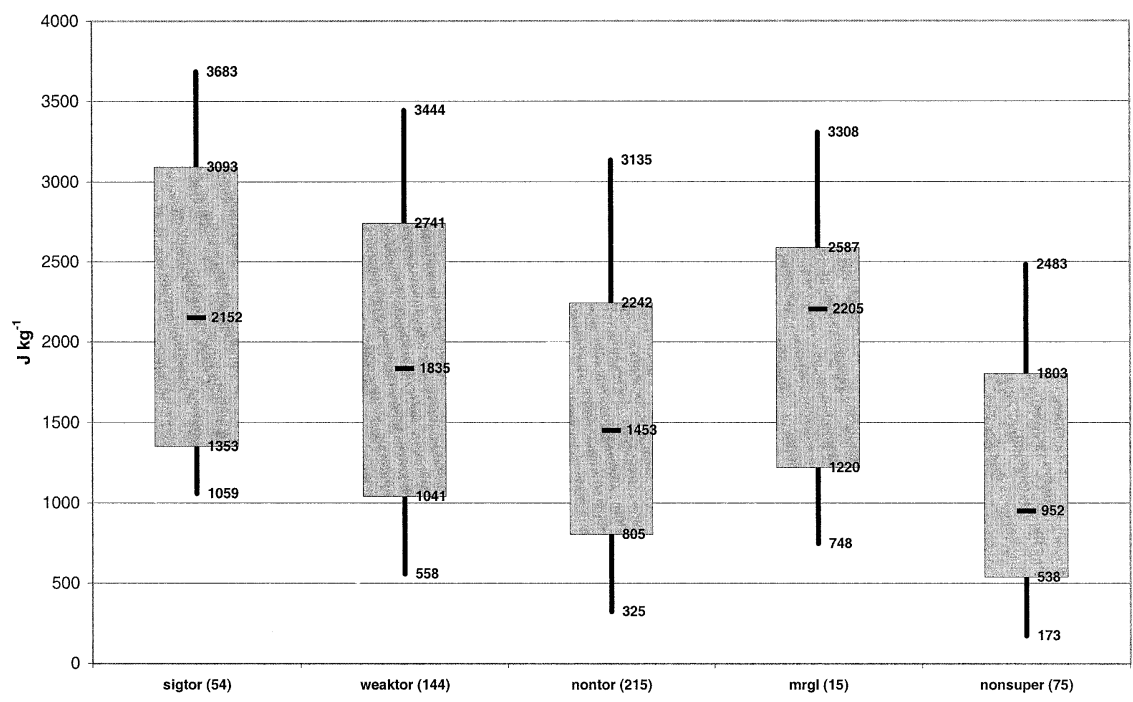

FIG. 6. Box and whiskers plot of MLCAPE values $\left(\mathrm{J} \mathrm{kg}^{-1}\right)$ with the significantly tornadic supercells (sigtor, 54 soundings), weakly tornadic supercells (weaktor, 144 soundings), nontornadic supercells (nontor, 215 soundings), "marginal" supercells (mrgl, 15 soundings), and a sample of discrete nonsupercell storms (nonsuper, 75 soundings). The shaded box covers the 25 th-75th percentiles, the whiskers extend to the 10 th and 90 th percentiles, and the median values are marked by the heavy horizontal line within each shaded box.

discrete nonsupercell storms ${ }^{4}$ and 15 storms with marginal supercell characteristics (e.g., cyclonic azimuthal shear less than $20 \mathrm{~m} \mathrm{~s}^{-1}$, or persistence of cyclonic shear for less than $30 \mathrm{~min}$ ) was collected. These storms served as comparison samples to the supercell groupings when we analyzed the environments associated with our different classes of convective storms. Though even larger sample size would be desirable, our sample sizes are reasonably consistent with comparable groupings in previous proximity sounding studies. Differing sample sizes may also impact the statistical interpretation of our results, but we believe our samples are sufficiently representative to allow comparisons among the storm groups.

\section{a. Thermodynamic parameters}

From the box and whiskers plot shown in Fig. 6, it is clear that larger MLCAPE values tend to increase monotonically, on average, from the nonsupercell storms to the significantly tornadic supercells. The values of MLCAPE for significantly tornadic and nontornadic supercells are offset by almost one quartile from the 25 th to 75 th percentiles of each distribution, and application of a one-sided Student's $t$ test for equal and unequal variances (Milton and Arnold 1990) revealed that the difference in the means is statistically significant

\footnotetext{
${ }^{4}$ These storms were all associated with radar reflectivity maxima in excess of $40 \mathrm{dBZ}$ for a period exceeding $30 \mathrm{~min}$, but they did not meet any of our supercell criteria outlined in section 2 .
}

at the $95 \%$ confidence level ( $\alpha=0.05$; see Table 2 ). Forecasting experience of the authors suggests that the differences in MLCAPE values across the storm groups are of meteorological significance only when comparing the more extreme events (e.g., significantly tornadic to nonsupercell), and of little operational use when attempting to discriminate between adjacent groups (e.g., weakly tornadic and nontornadic). These results are similar to the findings of RB98, Edwards and Thompson (2000), and C02.

These same studies have identified lifting condensation level (LCL) height as an important discriminator between significantly tornadic and nontornadic supercells. Our RUC-2 proximity sounding sample supports these findings, with a substantial offset (more than one quartile) in the percentile ranked values of MLLCL height between significantly tornadic and nontornadic supercells (Fig. 7). The differences in mean MLLCL heights across all storm groups are statistically significant (Table 2), though the differences appear to be operationally useful only when comparing the significantly tornadic and nontornadic supercells. The lower MLLCL heights of the significantly tornadic storms support the hypothesis of Markowski et al. (2002) that increased low-level relative humidity $(\mathrm{RH})$ may contribute to increased buoyancy in the rear flank downdraft, and an increased probability of tornadoes. The substantially higher MLLCL heights for the discrete nonsupercell storms may be misleading, in that our small sample did not include many storms within the moist regimes common to the Gulf coast and Florida during the summer (see discussion in section 2). 
TABLE 2. Comparison of mean RUC-2 proximity sounding parameter values for the significantly tornadic supercells (sigtor), nontornadic supercells (nontor), weakly tornadic supercells (weaktor), and nonsupercell storms (nonsuper). The difference in the mean values in each column is statistically significant at the $95 \%$ confidence level, except those italicized. Boldface numbers represent mean values with differences that are considered to be of meteorological significance to SPC forecasters.

\begin{tabular}{|c|c|c|c|c|c|c|c|c|}
\hline Mean values & Sigtor & Nontor & Sigtor & Weaktor & Weaktor & Nontor & Nontor & Nonsuper \\
\hline $\operatorname{MLCAPE}\left(\mathrm{J} \mathrm{kg}^{-1}\right)$ & 2303 & 1645 & 2303 & 1934 & 1934 & 1645 & 1645 & 1280 \\
\hline MLLCL (m AGL) & 1029 & 1410 & 1029 & 1250 & 1250 & 1410 & 1410 & 1919 \\
\hline $0-1-\mathrm{km}$ shear $\left(\mathrm{m} \mathrm{s}^{-1}\right)$ & 10.4 & 6.8 & 10.4 & 8.0 & 8.0 & 6.8 & 6.8 & 3.8 \\
\hline $0-6-\mathrm{km}$ shear $\left(\mathrm{m} \mathrm{s}^{-1}\right)$ & 25 & 23 & 25 & 23 & 23 & 23 & 23 & 8.4 \\
\hline $0-1-\mathrm{km}$ SRH $\left(\mathrm{m}^{2} \mathrm{~s}^{-2}\right)$ & 185 & 123 & 185 & 156 & 156 & 123 & 123 & 15 \\
\hline $0-3-\mathrm{km}$ SRH $\left(\mathrm{m}^{2} \mathrm{~s}^{-2}\right)$ & 250 & 180 & 250 & 210 & 210 & 180 & 180 & 49 \\
\hline BRN shear $\left(\mathrm{m}^{2} \mathrm{~s}^{-2}\right)$ & 72 & 54 & 72 & 57 & 57 & 54 & 54 & 9 \\
\hline $\mathrm{BRN}$ & 38 & 42 & 38 & 44 & 44 & 42 & 42 & 315 \\
\hline 0-1-km MLEHI & 2.7 & 1.3 & 2.7 & 1.9 & 1.9 & 1.3 & 1.3 & 0.1 \\
\hline $\mathrm{SCP}$ & 9.9 & 4.3 & 9.9 & 5.8 & 5.8 & 4.3 & 4.3 & 0.2 \\
\hline STP & 3.4 & 1.2 & 3.4 & 2.0 & 2.0 & 1.2 & 1.2 & .02 \\
\hline
\end{tabular}

\section{b. Vertical shear parameters}

Cloud model simulations by Weisman and Klemp (1982), along with observational studies by Markowski et al. (1998), RB98, and Bunkers (2002), indicate that a vector shear magnitude of roughly $15-20 \mathrm{~m} \mathrm{~s}^{-1}$ over the lowest $6 \mathrm{~km}$ is necessary to support supercells. Based on our RUC-2 proximity sounding samples, 0 $6-\mathrm{km}$ vector shear magnitudes commonly exceeded 20 $\mathrm{m} \mathrm{s}^{-1}$ for both tornadic and nontornadic supercells, with only a slight tendency for stronger shear in the significant tornado cases (Fig. 8). The $0-6-\mathrm{km}$ vector shear magnitude clearly discriminates between all supercells and nonsupercells, with no overlap in values between the 10th percentile for supercells $\left(\sim 15\right.$ to $\left.18 \mathrm{~m} \mathrm{~s}^{-1}\right)$ and the 90th percentile for nonsupercells $\left(\sim 14 \mathrm{~m} \mathrm{~s}^{-1}\right)$, and differences in the means between the supercell groups and nonsupercells are statistically significant (Table 2). Storms with "marginal" supercell characteristics were associated with $0-6-\mathrm{km}$ shear magnitudes in the tran- sition region between supercells and nonsupercells. Figure 8 suggests that supercells become more probable as $0-6-\mathrm{km}$ vector shear magnitude increases from 15 to $20 \mathrm{~m} \mathrm{~s}^{-1}(30-40 \mathrm{kt})$.

Differences between significantly tornadic and nontornadic supercells become more apparent when considering the vector shear magnitude in the lowest $1 \mathrm{~km}$ (Fig. 9). Vertical shear in this layer tends to be about $2.5-5 \mathrm{~m} \mathrm{~s}^{-1}(5-10 \mathrm{kt})$ stronger for the significantly tornadic supercells compared to the nontornadic supercells, and much weaker for the marginal supercells and nonsupercell storms (also see Table 2). Relatively large differences are also noted between the significantly tornadic and nontornadic supercells in terms of SRH (Davies-Jones et al. 1990). In agreement with work by Rasmussen (2003) using the RB98 sounding set, the majority of the difference in SRH between significantly tornadic and nontornadic supercells is in the $0-1-\mathrm{km}$ layer (Fig. 10). The differences between the significantly

MLLCL

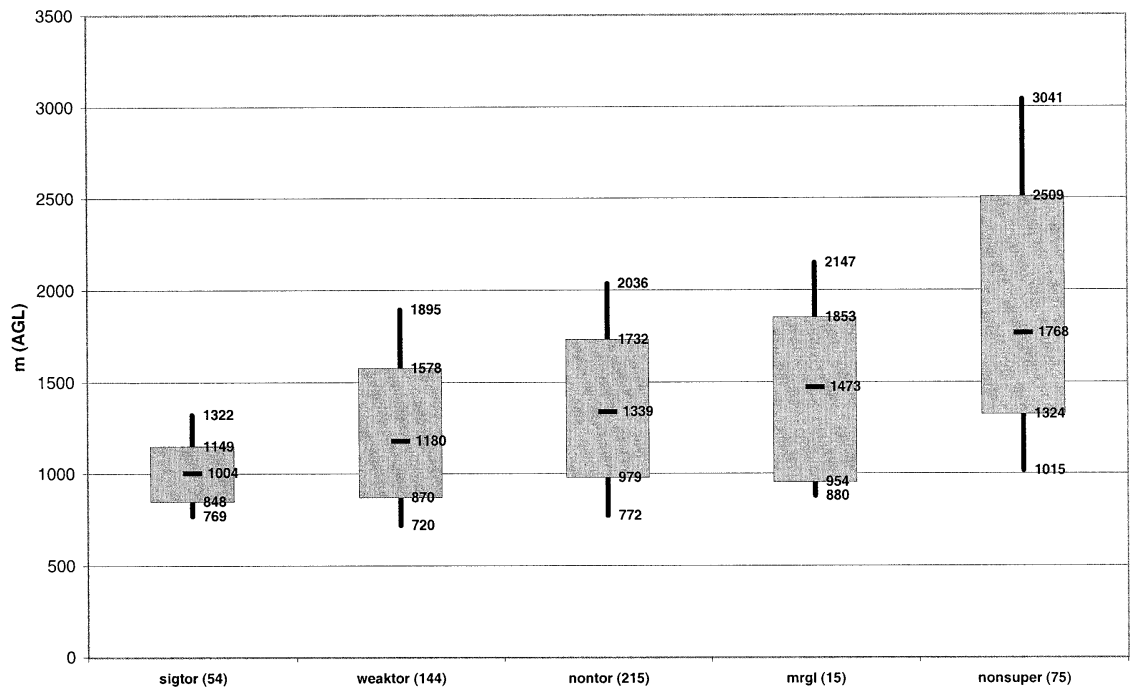

FIG. 7. Same as in Fig. 6 except for MLLCL height (m, AGL). 
0 6-km VECTOR SHEAR MAGNITUDE

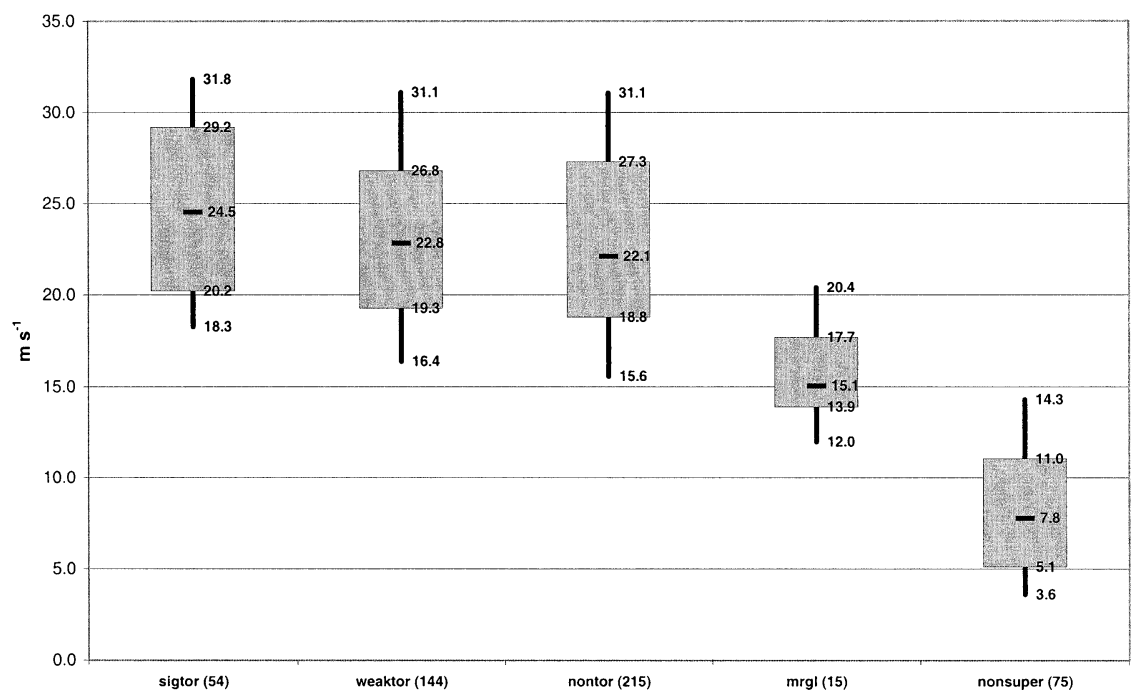

FIG. 8. Same as in Fig. 6 except for $0-6-\mathrm{km}$ vector shear magnitude $\left(\mathrm{m} \mathrm{s}^{-1}\right)$.

tornadic and nontornadic groups are the same when the storm motion algorithm developed by Bunkers et al. (2000) is applied to the proximity soundings (cf. Figs. 10 and 11). A more detailed statistical examination of the full RUC-2 proximity wind profiles can be found in a companion study by Markowski et al. (2003). The full vertical resolution model analyses may have supported larger values of $0-1-\mathrm{km}$ wind shear, though only the coarser 25-hPa resolution data were available in forecast operations at the SPC.

Based on the parameter distributions, the combined degree of low-level shear (e.g., 0-1-km SRH) and lowlevel moisture can strongly discriminate between sig- nificantly tornadic and nontornadic supercells. A majority $(81 \%)$ of the significantly tornadic supercells were associated with $0-1-\mathrm{km}$ mean $\mathrm{RH}>65 \%$ and $0-1-\mathrm{km}$ SRH $>75 \mathrm{~m}^{2} \mathrm{~s}^{-2}$, while $70 \%$ of the nontornadic supercells occurred with lesser values of either parameter (Fig. 12).

\section{c. Midlevel storm-relative winds}

An original motivating factor for this work was to refine the ability to discriminate between tornadic and nontornadic supercells in operational forecasting, after Brooks et al. (1994b) and Thompson (1998, hereafter

0-1-km VECTOR SHEAR MAGNITUDE

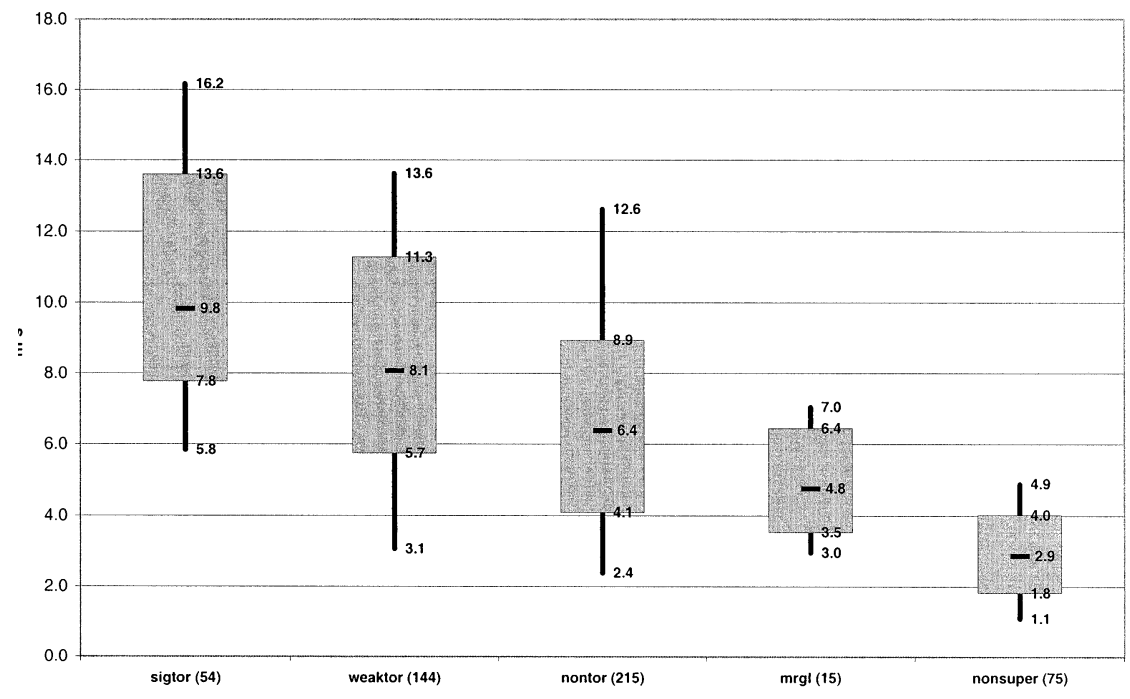

FIG. 9. Same as in Fig. 6 except for the $0-1-\mathrm{km}$ vector shear magnitude $\left(\mathrm{m} \mathrm{s}^{-1}\right)$. 


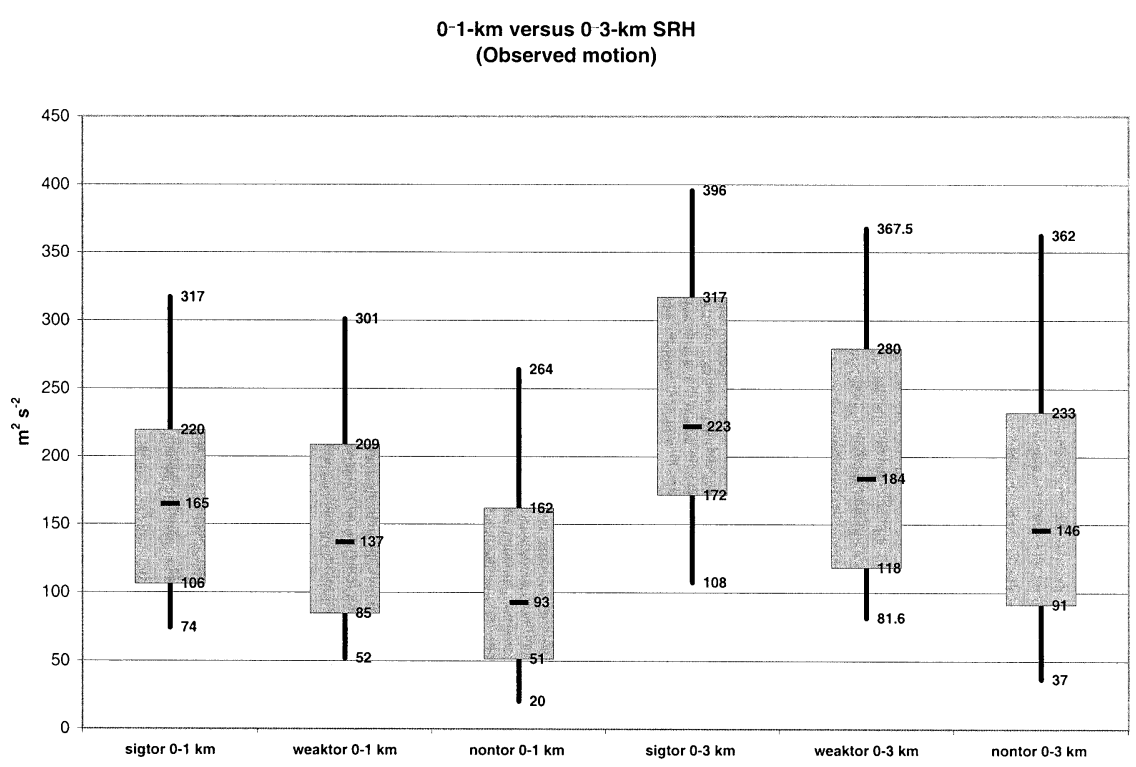

FIG. 10. Box and whiskers plot of 0-1- and 0-3-km SRH $\left(\mathrm{m}^{2} \mathrm{~s}^{-2}\right)$ for the sigtor, weaktor, and nontor groups, respectively. Plot conventions are similar to Fig. 6, and SRH calculations are based on observed storm motions.

T98). T98 found that storm-relative (SR) winds, derived from Eta Model analysis grids, were stronger at $500 \mathrm{hPa}$ for tornadic supercells, and weaker for nontornadic supercells. The mean SR wind speeds with each storm group were offset by one standard deviation, and application of a $t$ test confirmed that the difference in the means was significant at the $99 \%$ confidence level. An apparent threshold for tornadic supercells was noted at a $500-\mathrm{hPa}$ SR wind speed of about $8 \mathrm{~m} \mathrm{~s}^{-1}(\sim 15 \mathrm{kt})$. The middle troposphere was represented by $500 \mathrm{hPa}$ because only mandatory pressure level analyses were available at the time, and $700-\mathrm{hPa}$ winds were used to estimate storm motion as part of a forecast test in T98. At the time, it was suggested that a more robust method should be used to calculate a layer average in the middle troposphere, as improved operational software allowed use of higher-resolution model analysis grids.

Unfortunately, the increased horizontal and vertical resolution of the RUC-2 analyses compared to the Eta used in T98 (40 versus $80 \mathrm{~km}$, and roughly five levels versus one, respectively), and more stringent temporal constraints, did not result in any improvement on the

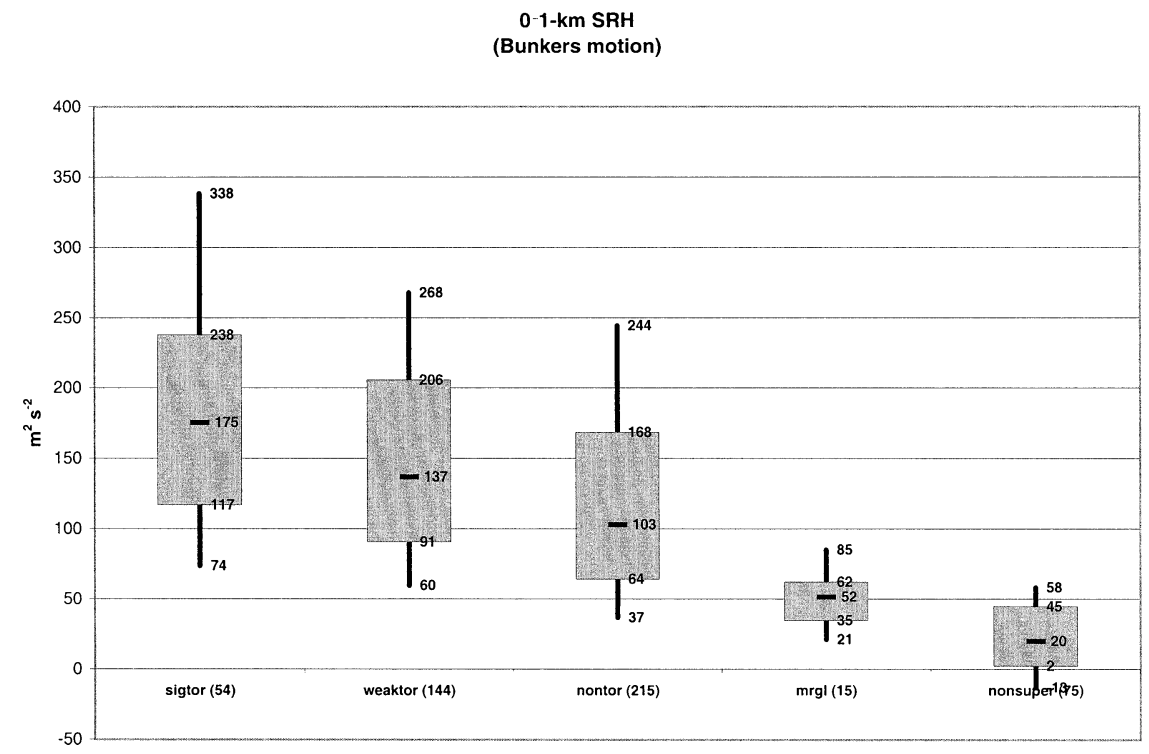

FIG. 11. Box and whiskers plot (same conventions as in Fig. 6) except for 0-1-km SRH $\left(\mathrm{m}^{2}\right.$ $\mathrm{s}^{-2}$ ) estimated via the Bunkers et al. (2000) storm motion algorithm for all five storm groups. 


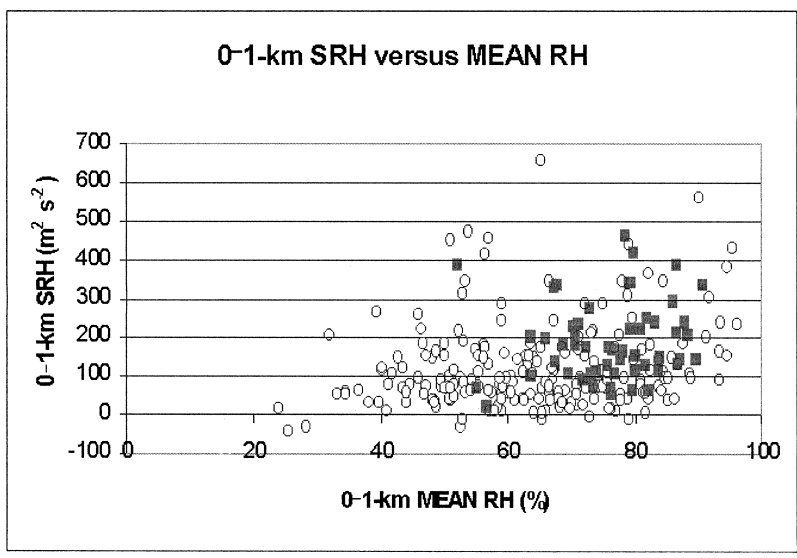

FIG. 12. Scatter diagram of $0-1-\mathrm{km} \mathrm{SRH}\left(\mathrm{m}^{2} \mathrm{~s}^{-2}\right.$, using observed storm motions) and $0-1-\mathrm{km}$ mean relative humidity (RH, \%) for the sigtor soundings (solid squares) and nontor soundings (open circles). An RH value of $65 \%$ and $0-1-\mathrm{km} \mathrm{SRH}$ of $75 \mathrm{~m}^{2} \mathrm{~s}^{-2}$ are highlighted by heavy lines within the plot.

findings of T98. Storm-relative winds using two different storm motions were calculated in the $4-6-\mathrm{km}$ layer (above RUC-2 ground level) for our entire supercell sample (Fig. 13). Analysis of SR wind speeds using observed storm motions reveals that the majority of significantly tornadic supercells were associated with SR wind speeds greater than $9 \mathrm{~m} \mathrm{~s}^{-1}(\sim 18 \mathrm{kt})$, though there was considerable overlap between the two groups throughout the distributions. The difference in the means between significantly tornadic $\left(12.0 \mathrm{~m} \mathrm{~s}^{-1}\right)$ and nontornadic supercells $\left(10.6 \mathrm{~m} \mathrm{~s}^{-1}\right)$, based on observed storm motions, was significant at the $95 \%$ confidence level. The companion study by Markowski et al. (2003) examined mean SR wind speeds as a function of height from the same RUC- 2 proximity sounding set and also found statistically significant differences in SR wind speeds associated with nontornadic and significantly tornadic supercells in the $3-5.5 \mathrm{~km}$ AGL layer (their Fig. $5)$.

The Bunkers et al. (2000) supercell motion algorithm was also examined with respect to SR wind speeds. As can be seen in Fig. 13, the small skew in the distributions was reversed compared to the observed motions, where the Bunkers method tended to underforecast 4-6-km SR wind speeds in significantly tornadic supercell environments. The Bunkers algorithm is apparently unable to replicate observed supercell motion with enough precision to preserve any small differences in 4-6-km SR wind speed between the two supercell groups. Given typical forecast storm motion errors and the relatively small differences between significantly tornadic and nontornadic supercells in this parameter space, the 46-km SR wind speed does not appear to be a suitable parameter for discrimination between tornadic and nontornadic supercells.

\section{d. Composite parameters}

\section{1) 0-1-KM ENERGY-HELICITY INDEX}

Hart and Korotky (1991) developed the initial version of the nondimensional energy-helicity index (EHI) as a means to identify tornado potential by combining total CAPE with SRH in the lowest $3 \mathrm{~km}$ :

$$
\mathrm{EHI}=(\mathrm{CAPE} \times \mathrm{SRH}) / 160000 .
$$

More recently, Rasmussen (2003) revised a formulation

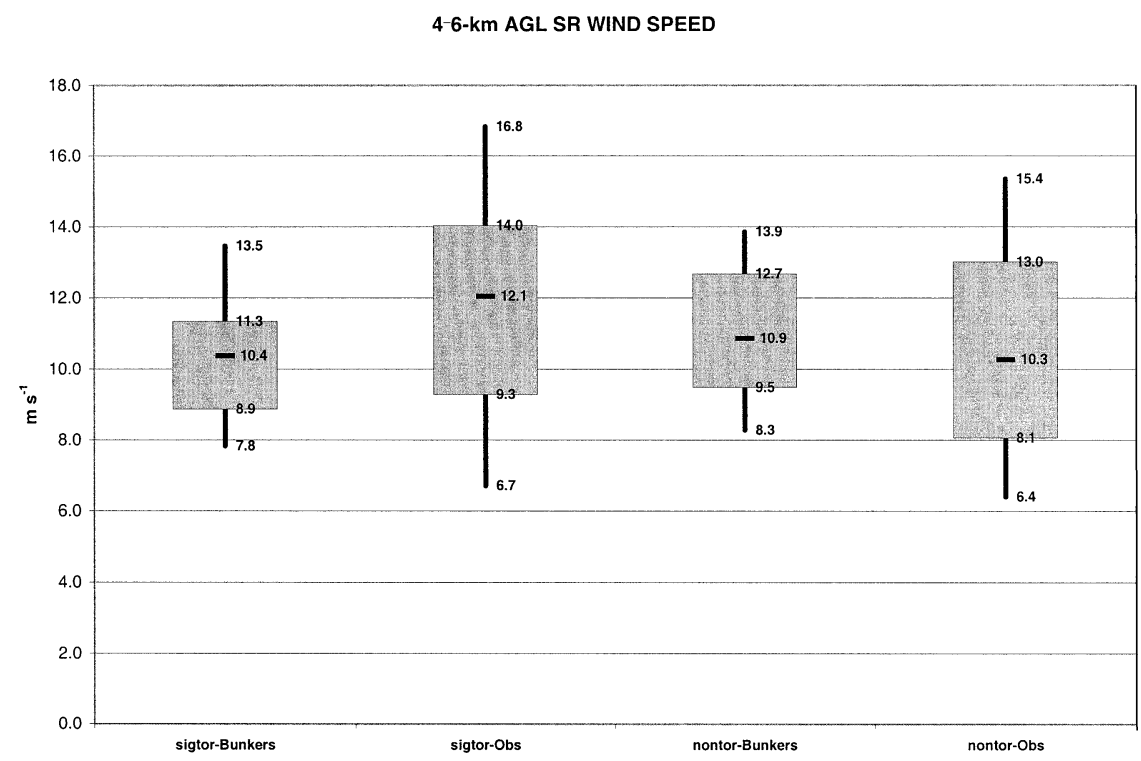

FIG. 13. Box and whiskers plot (same conventions as in Fig. 6), except for 4-6-km SR wind speed (kt) for the sigtor and nontor supercell groups. The 4-6-km SR wind speeds are based on the observed storm motions, and estimates from the Bunkers et al. (2000) storm motion algorithm. 


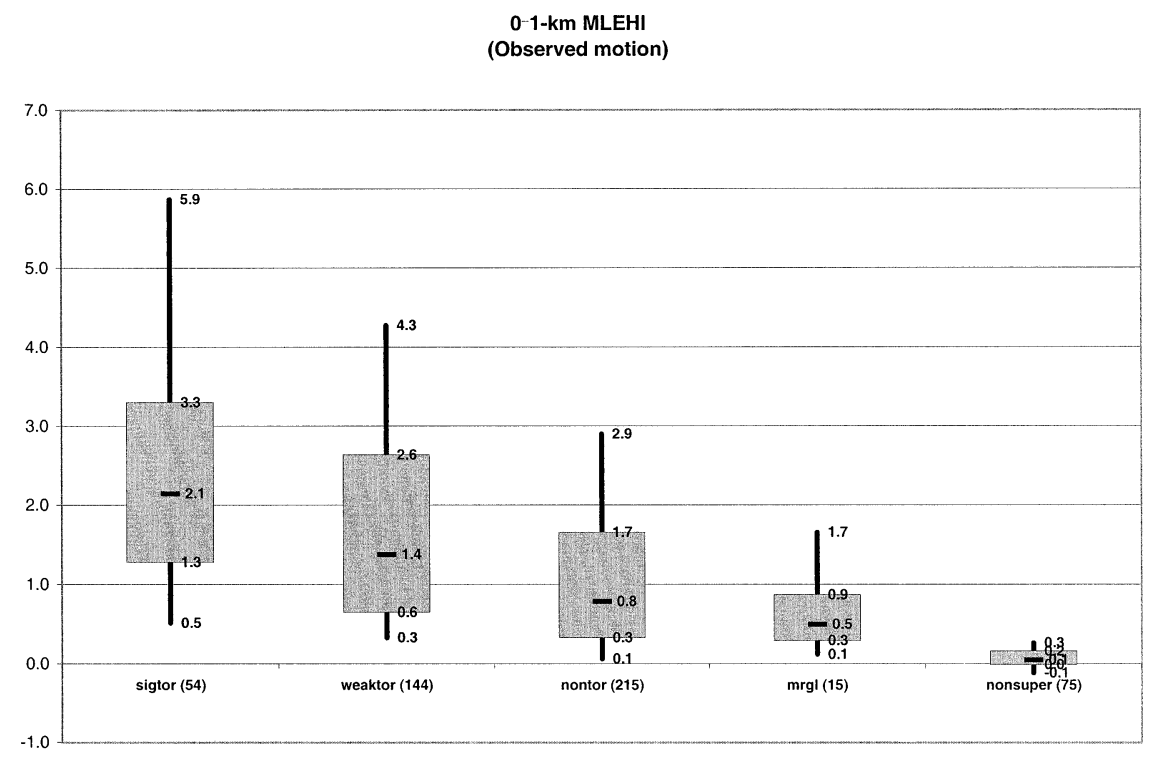

FIG. 14. Same as in Fig. 6 except for EHI based on MLCAPE and 0-1-km SRH (observed storm motion).

of EHI to focus on SRH in the lowest $1 \mathrm{~km}$, and this version of the EHI proved to be the best discriminator between tornadic and nontornadic storms in the RB98 dataset. In agreement with Rasmussen (2003), 0-1-km EHI (using MLCAPE, the MLEHI) values were offset by about 1.5 quartiles between nontornadic and significantly tornadic supercells when applied to the RUC-2 close proximity soundings (Fig. 14), with statistically significant differences in mean values across all adjacent storm groups (Table 1).

\section{2) BULK RICHARDSON NUMBER}

Weisman and Klemp (1982) examined the CAPE and vertical shear associated with cloud model simulations of thunderstorms, and combined the two parameters into a nondimensional ratio known as the bulk Richardson number (BRN). The BRN is inversely proportional to the vertical shear though the lowest $6 \mathrm{~km}$ and directly proportional to CAPE:

$$
\mathrm{BRN}=\mathrm{CAPE} / 0.5\left(U^{2}\right),
$$

where $U$ represents the difference between the densityweighted mean winds in the $0-6-\mathrm{km}$ and $0-500-\mathrm{m}$ layers. Values supportive of supercells that emerged from their work were approximately 10-50. Based on our sample of 413 supercell proximity soundings, BRN values (using MLCAPE) do discriminate rather well between supercells and nonsupercells, based on two quartiles of offset in BRN values between the middle 50\% of the storm groups (Fig. 15). Though roughly $25 \%$ of our supercell cases exceeded the approximate upper BRN threshold of 50 (Fig. 15), our findings are in reasonable agreement with Weisman and Klemp (1982). The separation between the supercells and nonsuper- cells, as well as between the supercell groups, improves when only the denominator (shear term) of the BRN (Fig. 16) is considered. The transition from nonsupercell to supercell storms occurs as BRN shear increases from 20 to $30 \mathrm{~m}^{2} \mathrm{~s}^{-2}$, whereas significantly tornadic supercells are usually associated with BRN shear values greater than $50 \mathrm{~m}^{2} \mathrm{~s}^{-2}$. Our findings support the earlier work by Stensrud et al. (1997), where they applied a BRN shear threshold of $40 \mathrm{~m}^{2} \mathrm{~s}^{-2}$ to tornado forecasting with a mesoscale model.

\section{3) Supercell composite PARAMETER}

The supercell composite parameter (SCP; Thompson et al. 2002) was conceived by SPC forecasters as a means to identify environments supporting supercells. ${ }^{5}$ The intent of the SCP was to normalize CAPE and measures of vertical shear to approximate threshold values for supercells, and combine these parameters into a single nondimensional parameter:

$$
\begin{aligned}
\mathrm{SCP}= & \left(\text { MUCAPE/1000 } \mathrm{J} \mathrm{kg}^{-1}\right) \\
& \times\left(0-3-\mathrm{km} \mathrm{SRH} / 100 \mathrm{~m}^{2} \mathrm{~s}^{-2}\right) \\
& \times\left(\text { BRN shear/40 } \mathrm{m}^{2} \mathrm{~s}^{-2}\right),
\end{aligned}
$$

where MUCAPE is the CAPE value based on the "most unstable" parcel in the lowest $300 \mathrm{mb}$. As any of the components decrease to near zero, the SCP approaches zero. The approximate threshold values used in each component were derived from distributions of each pa-

\footnotetext{
${ }^{5}$ We examined only right-moving (cyclonic in the Northern Hemisphere) supercells. Negative values of SRH can result in negative SCP values, which may be associated with left-moving (anticyclonic) supercells, based on the findings of Bunkers (2002).
} 
MLBRN

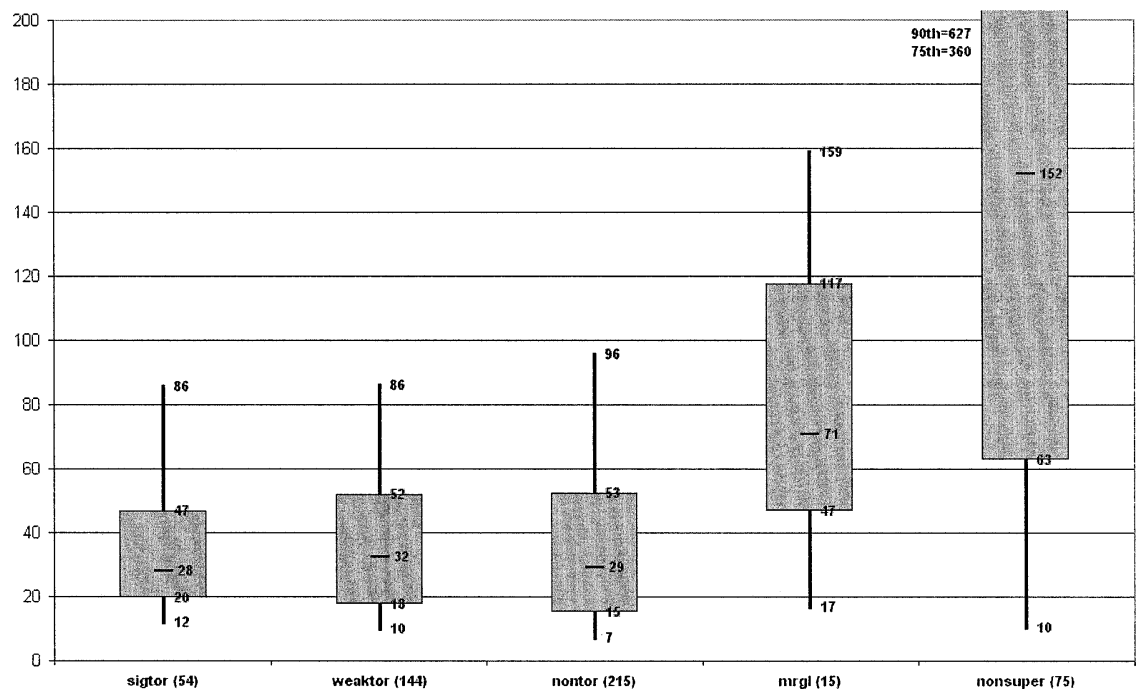

FIG. 15. Same as in Fig. 6 except for BRN based on the MLCAPE.

rameter in our dataset (e.g., see Fig. 10 for 0-3-km SRH value of $100 \mathrm{~m}^{2} \mathrm{~s}^{-2}$, and see Fig. 16 for the BRN shear value of $20 \mathrm{~m}^{2} \mathrm{~s}^{-2}$ ), as opposed to the more arbitrary SRH threshold of $150 \mathrm{~m}^{2} \mathrm{~s}^{-2}$ used in Thompson et al. (2002). Testing the SCP with the RUC-2 proximity soundings, it is seen that values of SCP greater than 1 strongly favor supercells, while nonsupercell storms are generally associated with SCP values less than 1 (Fig. 17). Mean SCP values exceeded 4 in all of the supercell groups, with a mean SCP value of only 0.2 for the nonsupercells. The SCP also appears to have some utility in differentiating between significantly tornadic and the other supercell groups, and the differences in the means were statistically significant across all categories (Table 2).

\section{4) SIGNIFICANT TORNADO PARAMETER}

The significant tornado parameter (STP) is similar to the SCP. The STP was developed and tested as a tool to aid operational forecasters in discriminating between significantly tornadic and nontornadic supercell environments (Thompson et al. 2002). CAPE and LCL height based on the lowest 100-hPa mean parcel, 0-1$\mathrm{km}$ SRH, and 0-6-km vector shear magnitude are all normalized to approximate threshold values for super-

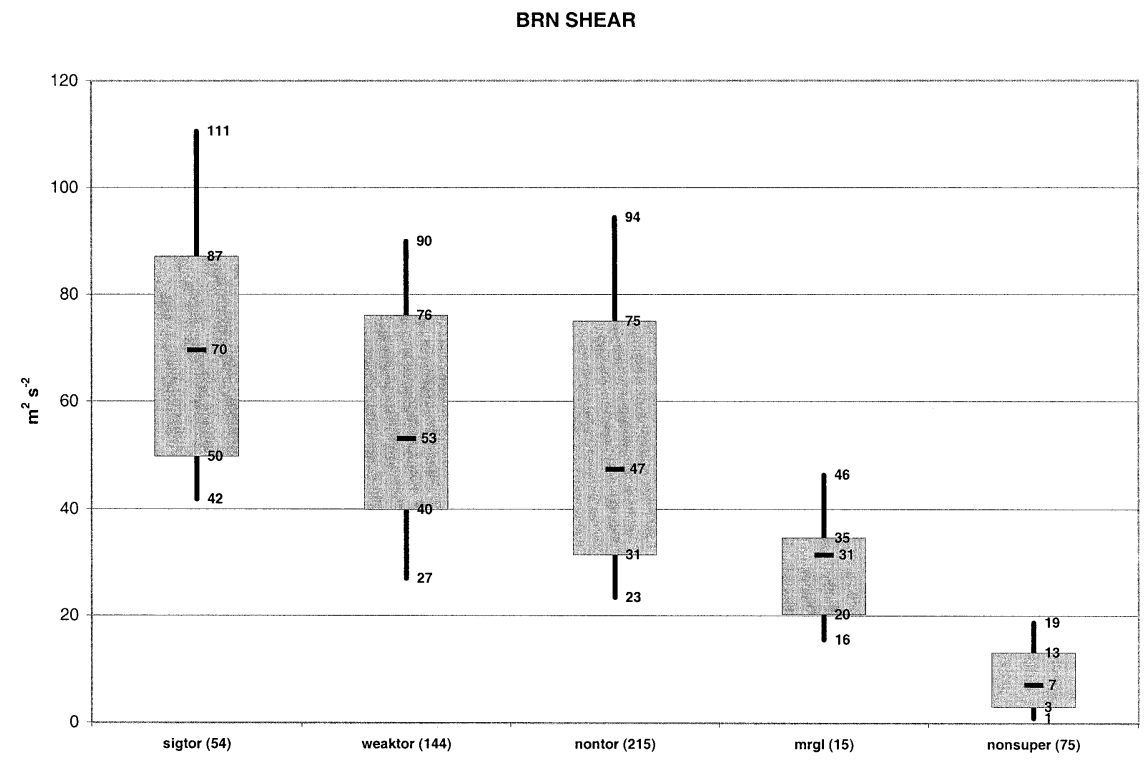

FIG. 16. Same as in Fig. 6, except for the BRN denominator $\left(\mathrm{m}^{2} \mathrm{~s}^{-2}\right)$. 


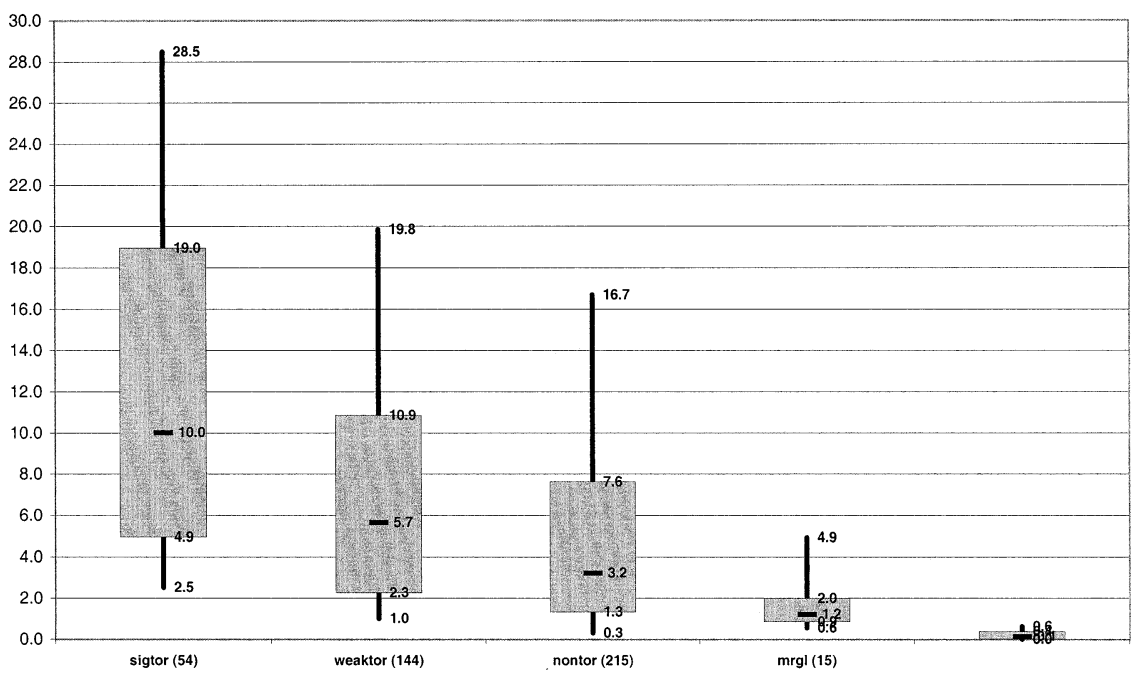

FIG. 17. Same as in Fig. 6 except for SCP using observed storm motion.

cells and significant tornadoes, and combined in a nondimensional parameter:

$$
\begin{aligned}
\mathrm{STP}= & \left(\text { MLCAPE } / 1000 \mathrm{~J} \mathrm{~kg}^{-1}\right)\left(\mathrm{SHR} 6 / 20 \mathrm{~m} \mathrm{~s}^{-1}\right) \\
& \times\left(\text { SRH} 1 / 100 \mathrm{~m}^{2} \mathrm{~s}^{-2}\right) \\
& \times[(2000-\text { MLLCL }) / 1500 \mathrm{~m}],
\end{aligned}
$$

where SHR6 is the vector shear magnitude from the surface to $6 \mathrm{~km}$ AGL, and SRH1 is the SRH in the 0$1-\mathrm{km}$ layer. This formulation produces an STP value of 1 when MLCAPE $=1000 \mathrm{~J} \mathrm{~kg}^{-1}, 0-6-\mathrm{km}^{-2}$ shear $=20$ $\mathrm{m} \mathrm{s}^{-1}, 0-1-\mathrm{km} \mathrm{SRH}=100 \mathrm{~m}^{2} \mathrm{~s}^{-2}$, and MLLCL $=500$ $\mathrm{m}$. As any of the CAPE or shear parameters approaches zero, the STP approaches zero. The STP also approaches zero as the MLLCL height increases to $2000 \mathrm{~m}$. As with the SCP, the approximate threshold values were derived from distributions of each parameter within our sample (i.e., see Fig. 6 for an MLCAPE value of $1000 \mathrm{~J} \mathrm{~kg}^{-1}$, Fig. 8 for a $0-6-\mathrm{km}$ vector shear magnitude of $20 \mathrm{~m}$ $\mathrm{s}^{-1}$, and Fig. 10 for the $0-1-\mathrm{km} \mathrm{SRH}$ value of $100 \mathrm{~m}^{2}$ $\mathrm{s}^{-2}$ ). Unlike the CAPE and shear terms, where values tend to be largest in association with significantly tornadic supercells, MCLCL heights tend to be lower for these same tornadic storms (see Fig. 7). The MLLCL height for a saturated parcel is effectively $500 \mathrm{~m}$, and the MLLCL term is formulated such that a value of 1 results when the ML parcel is saturated, decreasing to zero as the MLLCL height increases to $2000 \mathrm{~m}$ (MLLCL heights did not exceed $1750 \mathrm{~m}$ for any of our 54 significantly tornadic supercell soundings).

The STP distributions for the significantly tornadic and nontornadic supercells (Fig. 18) are offset by roughly two quartiles and based on a one-sided Student's $t$ test for both equal and unequal variances, the mean STP value for the significantly tornadic supercells (3.4) was significantly larger $(\alpha=0.005)$ than the mean value for the nontornadic supercells (1.2). To establish sound guidelines for use of STP in forecast operations, six different STP threshold values were examined as predictors of significant tornadoes within our dependent sample. After Doswell et al. (1990), $2 \times 2$ contigency tables were constructed for each STP threshold value, and a summary of statistical measures derived from these contingency tables is presented in Fig. 19 [refer to Doswell et al. (1990) for descriptions of each statistical measure]. An asymmetric penalty function in operational forecasting encourages low threshold values where the probability of detection (POD) is maximized, with less regard for the false alarm ratio (FAR). An example of such an approach would be the assumption that a significant tornado will occur based on the presence of a supercell, which results in a POD of 1, but an FAR of 0.87, in this sample. Such a decision threshold is effectively the climatological frequency of significant tornadoes with supercells in our sample (roughly one in eight supercells), which represents a no-skill forecast. Operational experience of the lead authors suggests that the actual frequency of significant tornadoes is likely lower than shown here.

Forecast skill is maximized for an STP value of 1 (see Fig. 19), where the POD remains 0.87 , and the frequency of correct null forecasts $(0.97)$ exceeds the climatology of null cases (0.87) in this sample. Considering the parameter distributions and statistical measures of forecast skill, an STP value of 1 appears to be a reasonable guideline to discriminate between significantly tornadic and nontornadic supercells. It is important to note that operational application of both the SCP and STP is very dependent on the ability to make accurate predictions of the convective mode, and these 
SIGNIFICANT TORNADO PARAMETER

(Observed motion)

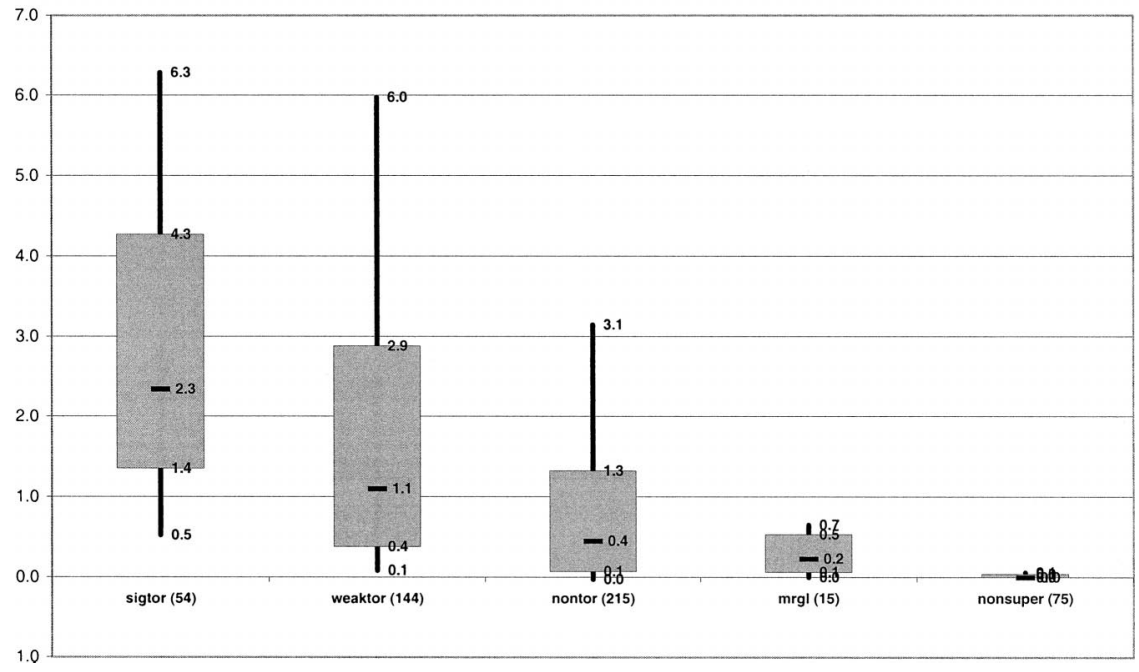

FIG. 18. Same as in Fig. 6, except for STP using observed storm motion.

parameters are not meant to be used in a "magic number" manner.

\section{Summary}

Analysis of a sample of 149 RUC-2 model analysis $(0 \mathrm{~h})$ and 125 one-hour forecast soundings suggests that the $R U C-2$ profiles are a reasonable proxy for direct observations in the regional supercell environment. Errors in the analysis and forecast soundings are generally within $0.5^{\circ} \mathrm{C}$ for temperatures, $0.2 \mathrm{~g} \mathrm{~kg}^{-1}$ for mixing ratios, and $1 \mathrm{~m} \mathrm{~s}^{-1}$ for wind speed (all close to the ranges for radiosonde accuracy). These basic variable errors contribute to typical MLCAPE error magnitudes of 250-500 J kg-1 (see Fig. 3), while derived shear parameters show no strong biases. Though these errors are

STP Forecast Threshold Comparison

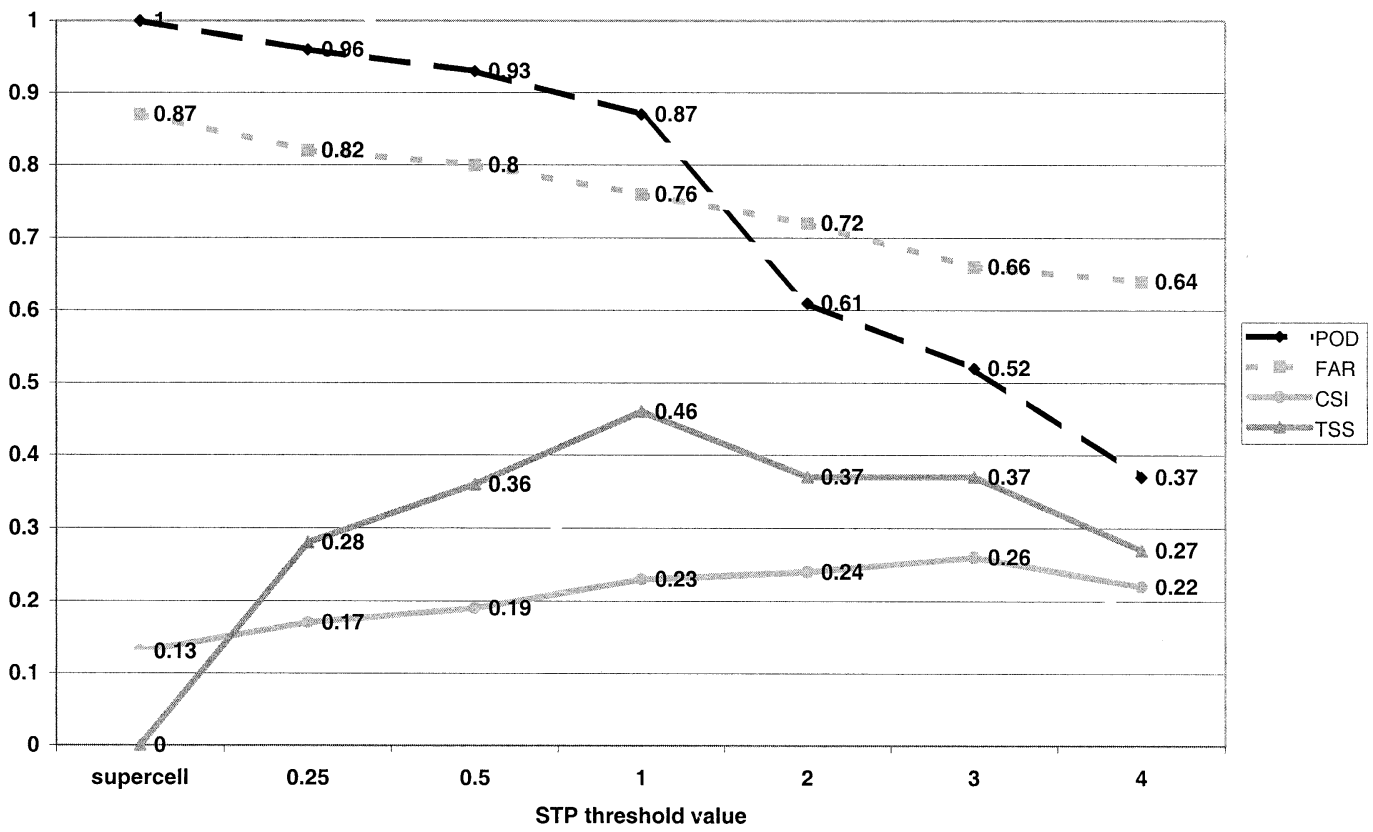

FIG. 19. Plot of POD (black dashed), FAR (gray dashed), critical success index (CSI, light gray solid), and true skill score (TSS, dark gray solid) for significant tornado forecasts based on six STP thresholds. Values for the "supercell" threshold represent the climatology of this 413 supercell sample. 
of concern to forecasters, approaches such as the hourly objective analysis scheme in use at the SPC (see Bothwell et al. 2002) can at least partially correct for RUC2 biases near the surface. Forecasters will still need to compare available observations to the RUC-2 analyses to identify important errors in the analysis soundings.

Several common thermodynamic and kinematic sounding parameters were calculated for a set of 413 RUC-2 close proximity supercell soundings, as well as a smaller sample of discrete nonsupercell storms. The RUC-2 analysis soundings revealed a tendency for greater CAPE and vertical shear to be associated with significantly tornadic supercells, and lesser values with nontornadic supercells and nonsupercell storms. Storm group mean values were statistically significant across the majority of the instability and vertical shear parameters examined, though the differences were only of meteorological significance when comparing the more extreme events (e.g., significantly tornadic and nontornadic supercells). Differences between significantly tornadic and nontornadic supercells were most pronounced in the $0-1-\mathrm{km}$ SRH and $0-1-\mathrm{km}$ RH or MLLCL height, while combination parameters such as SCP and STP showed the strongest ability to discriminate between the supercell types. It appears that the RUC-2 analyses retain the signals identified in previous and ongoing proximity soundings that utilize observed soundings.

The RUC-2 model (40-km resolution) is no longer an operational model, and has been replaced by a new 20-km resolution data assimilation and analysis system (the RUC20). Proximity soundings from the RUC20 model system have not yet been compared directly to the RUC-2 soundings. However, SPC forecasters have not identified any undesirable changes to the structure of hourly analysis soundings, nor to objective analyses derived from the hourly RUC20 analysis grids. In the absence of any evidence to the contrary, our findings based on the RUC-2 model soundings appear applicable to the new RUC20 system.

Acknowledgments. The authors would like to thank Steve Weiss (SPC) for his unwavering support of this project, and his careful review of an early draft of the manuscript. The detailed and thought-provoking comments provided by Matt Bunkers (NWS Rapid City, South Dakota), Brian Klimowski (NWS Flagstaff, Arizona), Barry Schwartz (FSL), and an anonymous reviewer all led to improved focus and clarity in this presentation. Finally, we have benefited from discussions with Jon Davies (private meteorologist). Jeff Craven (NWS Jackson, Mississippi), Jeff Evans (SPC), Erik Rasmussen (NSSL), and Dan Miller (NWS Norman, Oklahoma).

\section{REFERENCES}

Beebe, R. G., 1955: Types of airmasses in which tornadoes occur. Bull. Amer. Meteor. Soc., 36, 349-350.
—_ 1958: Tornado proximity soundings. Bull. Amer. Meteor. Soc., 39, 195-201.

Benjamin, S. G., and Coauthors, 2002: RUC20-The 20-km version of the Rapid Update Cycle. NOAA Tech. Memo. OAR FSL twentyeight. Forecast Systems Laboratory, Boulder, CO, 9 pp.

Bothwell, P. D., J. A. Hart, and R. L. Thompson, 2002: An integrated three-dimensional objective analysis scheme in use at the Storm Prediction Center. Preprints, 21st Conf. on Severe Local Storms, San Antonio, TX, Amer. Meteor. Soc., J117-J120.

Brooks, H. E., and J. P. Craven, 2002: Database of proximity soundings for significant severe thunderstorms, 1957-1993. Preprints, 21 st Conf. on Severe Local Storms, San Antonio, TX, Amer. Meteor. Soc., 639-642.

— C. C. A. Doswell III, and J. Cooper, 1994a: On the environments of tornadic and nontornadic mesocyclones. Wea. Forecasting, 9, 606-618.

— - , and R. B. Wilhelmson, 1994b: The role of midtropospheric winds in the evolution and maintenance of low-level mesocyclones. Mon. Wea. Rev., 122, 126-136.

Browning, K. A., 1964: Airflow and precipitation trajectories within severe local storms which travel to the right of the winds. $J$. Atmos. Sci., 21, 634-639.

Bunkers, M. J., 2002: Vertical wind shear associated with left-moving supercells. Wea. Forecasting, 17, 845-855.

—, B. A. Klimowski, J. W. Zeitler, R. L. Thompson, and M. L. Weisman, 2000: Predicting supercell motion using a new hodograph technique. Wea. Forecasting, 15, 61-79.

Craven, J. P., H. E. Brooks, and J. A. Hart, 2002a: Baseline climatology of sounding derived parameters associated with deep, moist convection. Preprints, 21st Conf. on Severe Local Storms, San Antonio, TX, Amer. Meteor. Soc., 643-646.

— R. E. Jewell, and H. E. Brooks, 2002b: Comparison between observed convective cloud-base heights and lifting condensation level for two different lifted parcels. Wea. Forecasting, 17, 885890.

Darkow, G. L., 1969: An analysis of over sixty tornado proximity soundings. Preprints, Sixth Conf. on Severe Local Storms, Chicago, IL, Amer. Meteor. Soc., 218-221.

—_ and D. W. McCann, 1977: Relative environmental winds for 121 tornado bearing storms. Preprints, 10th Conf. on Severe Local Storms, Omaha, NE, Amer. Meteor. Soc., 413-417.

Davies, J. M., and R. H. Johns, 1993: Some wind and instability parameters associated with strong and violent tornadoes. 1. Wind shear and helicity. The Tornado: Its Structure, Dynamics, Prediction, and Hazards, Geophys. Monogr., No. 79, Amer. Geophys. Union, 573-582.

Davies-Jones, R. P., D. W. Burgess, and M. Foster, 1990: Test of helicity as a tornado forecast parameter. Preprints, 16th Conf. on Severe Local Storms, Kananaskis Park, AB, Canada, Amer. Meteor. Soc., 588-592.

Doswell, C. A., III, and E. N. Rasmussen, 1994: The effect of neglecting the virtual temperature correction on CAPE calculations. Wea. Forecasting, 9, 625-629.

,$- \ldots$, R. Davies-Jones, and D. L. Keller, 1990: On summary measures of skill in rare event forecasting based on contingency tables. Wea. Forecasting, 5, 576-585.

Edwards, R., and R. L. Thompson, 2000: RUC-2 supercell proximity soundings, Part II: An independent assessment of supercell forecast parameters. Preprints, 20th Conf. on Severe Local Storms, Orlando, FL, Amer. Meteor. Soc., 435-438.

—_ — - and J. A. Hart, 2002: Verification of supercell motion forecasting techniques. Preprints, 21st Conf. on Severe Local Storms, San Antonio, TX, Amer. Meteor. Soc., J57-J60.

Fawbush, E. J., and R. C. Miller, 1954: The types of air masses in which North American tornadoes form. Bull. Amer. Meteor. Soc., 35, 154-165.

Grell, G. A., 1993: Prognostic evaluation of assumptions used by cumulus parameterizations. Mon. Wea. Rev., 121, 764-787.

Hart, J. A., and W. Korotky, 1991: The SHARP workstation vl.50 users guide. NOAA/National Weather Service. 30 pp. [Available 
from NWS Eastern Region Headquarters, 630 Johnson Ave., Bohemia, NY 11716.]

Johns, R. H., J. M. Davies, and P. W. Leftwich, 1993: Some wind and instability parameters associated with strong and violent tornadoes. 2. Variations in the combinations of wind and instability parameters. The Tornado: Its Structure, Dynamics, Prediction, and Hazards, Geophys. Monogr., No. 79, Amer. Geophys. Union, 583-590.

Kerr, B. W., and G. L. Darkow, 1996: Storm-relative winds and helicity in the tornadic thunderstorm environment. Wea. Forecasting, 11, 489-505.

Lemon, L. R., 1977: New severe thunderstorm radar identification techniques and warning criteria: A preliminary report. NOAA Tech. Memo. NWS NSSFC-1, 60 pp.

Maddox, R. A., 1976: An evaluation of tornado proximity wind and stability data. Mon. Wea. Rev., 104, 133-142.

Markowski, P. N., J. M. Straka, E. N. Rasmussen, and D. O. Blanchard, 1998: Variability of storm-relative helicity during VORTEX. Mon. Wea. Rev., 126, 2959-2971.

$\longrightarrow,-$, and - , 2002: Direct surface thermodynamic observations within the rear-flank downdrafts of nontornadic and tornadic supercells. Mon. Wea. Rev., 130, 1692-1721.

_ , C. Hannon, J. Frame, E. Lancaster, A. Pietrycha, R. Edwards, and R. Thompson, 2003: Characteristics of vertical wind profiles near supercells obtained from the Rapid Update Cycle. Wea. Forecasting, 18, 1262-1272.

Milton, J. S., and J. C. Arnold, 1990: Introduction to Probability and Statistics: Principles and Applications for Engineering and the Computing Sciences. McGraw-Hill, 700 pp.

NOAA, cited 2003: Systems and equipment. Rawinsonde and Pibal Observations, Federal Meteorological Handbook No. 3. [Available online at http://www.ofcm.gov/fmh3/text/chapter2.htm.]

Rasmussen, E. N., 2003: Refined supercell and tornado forecast parameters. Wea. Forecasting, 18, 530-535.

— ing-derived supercell and tornado forecast parameters. Wea. Forecasting, 13, 1148-1164.

Schaefer, J. T., and R. L. Livingston, 1988: The typical structure of tornado proximity soundings. J. Geophys. Res., 93, 5351-5364.
— and $-2002 \mathrm{~b}$ : Verification of RUC surface forecasts at major U.S. airport hubs. Preprints, 10th Conf. on Aviation, Range, and Aerospace Meteorology, Portland, OR, Amer. Meteor. Soc., 327330 .

Schwartz, B. E., and S. G. Benjamin, 2002a: An assessment of 3and 6-h RUC CAPE forecasts. Preprints, 21st Conf. on Severe Local Storms, San Antonio, TX, Amer. Meteor. Soc., J85-J88.

Showalter, A. K., and J. R. Fulks, 1943: Preliminary report on tornadoes. U.S. Weather Bureau, $162 \mathrm{pp}$.

Stensrud, D. J., J. V. Cortinas Jr., and H. E. Brooks, 1997: Discriminating between tornadic and nontornadic thunderstorms using mesoscale model output. Wea. Forecasting, 12, 613-632.

Stumpf, G. J., A. Witt, E. D. Mitchell, P. L. Spencer, J. T. Johnson, M. D. Eilts, K. W. Thomas, and D. W. Burgess, 1998: The National Severe Storms Laboratory mesocyclone detection algorithm for the WSR-88D. Wea. Forecasting, 13, 304-326.

Thompson, R. L., 1998: Eta Model storm-relative winds associated with tornadic and nontornadic supercells. Wea. Forecasting, 13, $125-137$.

—_ R. Edwards, and J. A. Hart, 2002: Evaluation and interpretation of the supercell composite and significant tornado parameters at the Storm Prediction Center. Preprints, 21st Conf. on Severe Local Storms, San Antonio, TX, Amer. Meteor. Soc., J11-J14.

Turner, D. D., B. M. Lesht, S. A. Clough, J. C. Liljegren, H. E. Revercomb, and D. C. Tobin, 2003: Dry bias and variability in Vaisala RS80-H radiosondes: The ARM experience. J. Atmos. Oceanic Technol., 20, 117-132.

Weisman, M. L., and J. B. Klemp, 1982: The dependence of numerically simulated convective storms on wind shear and buoyancy. Mon. Wea. Rev., 110, 504-520.

_- M. S. Gilmore, and L. J. Wicker, 1998: The impact of convective storms on their local environment: What is an appropriate ambient sounding? Preprints, 19th Conf. on Severe Local Storms, Minneapolis, MN, Amer. Meteor. Soc., 238-241.

Weiss, S. J., and M. D. Vescio, 1998: Severe local storms climatology 1995-1996: Analysis of reporting trends and implications for NWS operations. Preprints, 19th Conf. on Severe Local Storms, Minneapolis, MN, Amer. Meteor. Soc., 536-539.

Wilks, D. S., 1995: Statistical Methods in the Atmospheric Sciences. Academic Press, 467 pp. 